\title{
The nature of orthographic-phonological and orthographic-semantic relationships for Japanese kana and kanji words
}

\author{
Yasushi Hino • Shinobu Miyamura • Stephen J. Lupker
}

Published online: 10 May 2011

(C) Psychonomic Society, Inc. 2011

\begin{abstract}
It is generally assumed that orthographic-phonological (O-P) consistencies are higher for Japanese kana words than for kanji words and that orthographic-semantic (O-S) consistencies are higher for kanji words than for kana words. In order to examine the validity of these assumptions, we attempted to measure the O-P and O-S consistencies for 339 kana words and 775 kanji words. Orthographic neighbors were first generated for each of these words. In order to measure the O-P consistencies of the words, their neighbors were then classified as phonological friends or enemies, based on whether the characters shared with the original word were pronounced the same in the two words. In order to measure the O-S consistencies, the similarity in meaning of each of the neighbors to the original word was rated on a 7-point scale. Based on the ratings, the neighbors were classified as semantic friends or enemies. The results indicated that both the O-P consistencies for kanji words and the O-S consistencies for kana words were greater than previously assumed and that the two scripts were actually quite similar on both types of consistency measures. The implications for the nature of the reading processes for kana and kanji words are discussed.
\end{abstract}

\footnotetext{
Y. Hino $(\square)$

Faculty of Arts and Sciences, Waseda University,

1-24-1 Toyama, Shinjuku-ku,

Tokyo 162-8644, Japan

e-mail: hino@waseda.jp

S. Miyamura

Net-Research Department, Custom Research Management Unit,

INTAGE Inc,

Tokyo, Japan

S. J. Lupker

Department of Psychology, University of Western Ontario,

London, Ontario, Canada
}

Keywords Orthographic-phonological consistency. Orthographic-semantic consistency · Japanese kana words . Japanese kanji words

One of the most salient characteristics of the Japanese language is that words are printed in multiple scripts: kanji, hiragana, and katakana. Kanji is a logographic script, and each kanji character directly represents meaning. Thus, each kanji character is considered to be a morpheme. In contrast, kana scripts, consisting of hiragana and katakana, are phonetic scripts, and hence each kana character corresponds to a mora, a rhythmic unit of a constant duration consisting of either a single vowel or a combination of a consonant and a vowel. Although any kanji word can be transcribed into either katakana or hiragana based on its pronunciation, most words are typically printed in only a single script. In Japanese sentences, nouns, adverbs, and verb and adjective stems are typically written in kanji. Grammatical elements such as auxiliary verbs and particles are typically written in hiragana, whereas a number of special types of words (e.g., foreign loan words, animal names, scientific terms, etc.) are typically written in katakana.

For most Japanese words, therefore, word frequency counts are available only for one script form. There are some exceptions, however. For example, the word "glasses" normally appears in all three scripts (katakana メガネ, hiragana めが祇, and kanji 眼鏡), and therefore, all the script forms have their respective frequency counts. ${ }^{1}$

\footnotetext{
'According to Amano and Kondo's (2003b) word frequency norms, the frequency counts of the word "glasses," respectively, among 287,792,797 tokens, are 667 for the katakana script form, メガネ; 253 for the hiragana script form, めがね; and 1,314 for the kanji script form, 眼鏡. In contrast, the frequency count for the word ラジオ (radio) is listed only for the katakana script form, which is 8,696. Similarly, the frequency count for the word 台所 (kitchen) is available only for the kanji script form, which is 3,239.
} 


\section{Different relationships between orthography, phonology, and semantics for kana and kanji words}

The central issue investigated in the present research is the suggestion by a number of researchers that the nature of the relationships between orthography and phonology and between orthography and semantics must be quite different for words printed in kana and kanji (e.g., Feldman \& Turvey, 1980; Frost, 2005; Kimura, 1984; Saito, 1981; Wydell, Butterworth, \& Patterson, 1995). Because each kana character generally corresponds to a single mora, kana is considered a shallow orthography, in which the relationships between the kana characters and their sounds (i.e., the orthographic-phonological [O-P] relationships) are quite transparent. That is, whenever the same kana character is used, it is almost always pronounced the same, as in イス (chair, /i.su/) and リス(squirrel, /ri.su/). In contrast, kanji is considered a deep orthography, in which the charactersound relationships are rather opaque. Often, kanji characters have at least two potential pronunciations: the so-called kun-reading and on-reading pronunciations. ${ }^{2}$ The kunreadings are of Japanese origin and were assigned to the kanji characters based on their meanings. On the other hand, the on-readings are of Chinese origin, and these pronunciations were imported from China together with these characters. In addition, a number of kanji characters have more than one on-reading pronunciation, due to the fact that Chinese pronunciations themselves changed over time for the same characters and that pronunciations were imported from China several times in history. As a result, kanji characters are pronounced in different ways in different contexts [e.g., 親父 (father, /o.ja-zi/) and 親戚 (relatives, $/$ si.N-se.ki/)], suggesting that the O-P relationships for kanji words are much less consistent than those for kana words. ${ }^{3}$

In contrast, it is generally assumed that the orthographicsemantic (O-S) relationships are much more consistent for kanji words than for kana words (e.g., Feldman \& Turvey, 1980; Frost, 2005; Ijuin, 2008; Kimura, 1984; Saito, 1981; Wydell et al., 1995). As previously noted, because each kanji character is a morpheme, it denotes a specific meaning. Thus,

\footnotetext{
According to Tamaoka, Kirsner, Yanase, Miyaoka, and Kawakami (2002), 777 out of 1,945 basic kanji characters have only a single pronunciation $(40.05 \%)$, indicating that about $60 \%$ of kanji characters possess multiple pronunciations in Japanese.

${ }^{3}$ When we describe morae using characters from the Roman alphabet, we will use the format from Tamaoka and Makioka (2004), with the following exceptions: (1) a period [.] is used to denote a moraic boundary, (2) a hyphen [-] is used to denote a morphemic boundary [e.g., /si.N-se.ki/ for 親戚 (relatives)], and (3) a prolonged ("long") vowel is denoted by using two vowel symbols, with the second one being capitalized [e.g., /te.E.pu/ instead of /te.R.pu/ for テープ (tape)].
}

it is likely that words containing the same kanji character tend to share (at least a part of) their meaning, such as with 男性 (male, /da.N-se.i/) and 男子 (boy, /da.N-si/). Kana characters, in contrast, are phonetic characters. Therefore, although words sharing the same kana characters may tend to have similar pronunciations, there is no a priori reason to expect that they would share meanings [e.g., ポケット (pocket, /po. ke.Q.to/) and ロケット (rocket, /ro.ke.Q.to/)].

\section{Empirical findings}

The assumptions that O-P consistencies are much higher for kana words than for kanji words and that O-S consistencies are much higher for kanji words than for kana words appear to lead to the theoretical position that there are definite processing differences for kana and kanji words. For example, some researchers (e.g., Morton \& Sasanuma, 1984; Saito, 1981) have suggested that completely different processes are involved in phonological coding for kana and kanji words, along the lines of the assumptions made by the orthographic depth hypothesis (e.g., Frost, 2005; Frost, Katz, \& Bentin, 1987). According to this position, phonological coding for a kana word is assumed to be accomplished by simply applying print-sound correspondence rules (i.e., an "assembly" route like that found in the dual-route cascaded model - Coltheart, Rastle, Perry, Langdon, \& Ziegler, 2001). In contrast, because word-level information would have to be retrieved first in order to correctly name a kanji word, phonological coding for kanji words can only be accomplished via the mental lexicon (i.e., a "lexical" route-e.g., Wydell et al., 1995). At the same time, given the higher O-S consistencies for kanji than for kana words, this position also assumes that, although the process of retrieving lexical/semantic information is driven directly by orthography for kanji words, this process is mediated by phonology for kana words.

Empirical evidence consistent with this position had been reported in some previous studies. For example, Feldman and Turvey (1980) and Saito (1981) compared naming latencies for the same words written in kana and kanji scripts. Using words normally written in kanji (i.e., color names), the naming latencies were faster when the words were transcribed into hiragana than when they were presented in kanji. In contrast, Saito also reported that, using a task requiring a response based on the meanings of the presented word (a sentence judgment task), response latencies were faster when the words were presented in the familiar kanji script than when they were transcribed into hiragana.

Wydell et al. (1995) also reported data generally consistent with this position in their naming experiments 
using kanji words. In their experiments, naming performance was compared for kanji words that consisted of kanji characters with only a single pronunciation (the consistent condition) and kanji words that consisted of kanji characters with multiple pronunciations (the inconsistent condition). If the naming of kanji words is performed not only via the lexical route but also through some sort of assembly route using character-sound correspondence rules, naming latencies should be slower for words consisting of kanji characters with multiple pronunciations, because there is a possibility that the assembly route could produce conflicting outputs for these words. In their six naming experiments, however, Wydell et al. failed to find a consistency effect and, hence, concluded that phonological coding for kanji words is accomplished only via a lexical route.

Kimura (1984) also reported data indicating that the process of retrieving lexical/semantic information is directly driven by orthography for kanji words but is mediated by phonology when kanji words are transcribed into kana. Kimura examined the effect of concurrent articulation using a relatedness judgment task with the same word pairs either presented in kanji (their typical script) or transcribed into hiragana. In the concurrent articulation condition, participants were asked to repeatedly count from 1 to 5 aloud while deciding whether or not each word pair was related. In this task, relatedness judgment performance was more disrupted by concurrent articulation when the word pairs were transcribed into hiragana than when they were presented in kanji. Based on these results, Kimura suggested that (1) relatedness judgment performance was more disrupted for hiragana transcription pairs because the concurrent articulation disrupts prelexical phonological coding and that (2) the effect of the concurrent articulation was smaller for kanji word pairs because word meanings could be directly retrieved from orthography for those words.

Although there are now a number of findings that are consistent with the predictions for kanji and kana words derived from an orthographic-depth-type hypothesis, more recently this position has been criticized by some researchers. According to this type of hypothesis, a processing advantage would always be expected for kana-written forms over kanji-written forms of the same words in naming. Yamada (1992), however, reported data inconsistent with this prediction. In his naming task, kanji numerals were named slightly faster than their hiragana transcriptions. In addition, Besner and Hildebrandt (1987) reported data inconsistent with the claim that kanawritten words are always named only via a shallow, assembly-like process. If phonological coding for kanawritten stimuli is always accomplished through an assembly route, there would be no reason to expect effects of orthographic familiarity or lexicality on the naming of kana-written stimuli. Besner and Hildebrandt, therefore, compared naming performance for (1) familiar katakana words that are normally written in katakana, (2) unfamiliar katakana transcriptions of words that are normally written in kanji, and (3) katakana-written nonwords. The naming responses for the katakana words were faster than those for the katakana transcriptions of kanji words, which were faster than those for the katakana nonwords. Consistent with these findings, Hino and Lupker (1998) also reported significant word frequency effects for both katakana and kanji words in their naming experiments.

In order to account for the fact that orthographic familiarity, word frequency, and lexicality affect naming performance for the kana-written stimuli, lexical involvement in the phonological-coding process would have to be assumed. Taking a dual-route perspective (e.g., Coltheart, 1978, 2005; Coltheart, Curtis, Atkins, \& Haller, 1993; Coltheart et al., 2001), therefore, Besner and Hildebrandt's (1987) and Hino and Lupker's (1998) data suggest that phonological coding for kana-written stimuli involves not only an assembly route but also a lexical route.

Similarly, Fushimi, Ijuin, Patterson, and Tatsumi (1999) suggested that phonological coding for kanji words also involves both routes. As noted, Wydell et al. (1995) failed to observe a consistency effect for kanji words in their naming experiments, with their consistency manipulation being based on the number of pronunciations possessed by the constituent kanji characters. Simply manipulating the number of pronunciations possessed by the constituent characters may not necessarily produce a strong manipulation of O-P consistency, however. That is, even when a kanji character has multiple pronunciations, the inconsistency would be substantially diminished if that character is pronounced the same way whenever it is used in a specific character position in kanji words. In order to address this issue, Fushimi et al. (1999) manipulated the O-P consistency for kanji words based on the pronunciations of their orthographic neighbors (Coltheart, Davelaar, Jonasson, \& Besner, 1977), following the procedure used by Jared, McRae, and Seidenberg (1990). Using this consistency manipulation, Fushimi et al. reported a significant consistency effect in the naming of kanji words.

Similarly, using katakana words with macrons, Hino, Kusunose, Lupker, Kawarada, and Maekawa (2011) recently manipulated O-P consistencies for katakana words based on the pronunciations of their orthographic neighbors and reported a consistency effect in the naming of katakana words. A reasonable interpretation of this effect is that it arises due to the competition created by conflicting outputs 
from the lexical and assembly routes during the phonological-coding process for the inconsistent words. The consistency effects in the naming of kanji and katakana words, therefore, strongly suggest that, if one takes a dual-route perspective, both the lexical and assembly routes are involved in the naming of both kanji and katakana words. ${ }^{4}$

Note also that some semantic effects have been reported in the naming not only of kanji words (e.g., Hino, Lupker, \& Pexman, 2002; Shibahara, Zorzi, Hill, Wydell, \& Butterworth, 2003) but also of katakana words (e.g., Hino, Lupker, Sears, \& Ogawa, 1998). These data also indicate that neither kanji words nor kana words are named only via an assembly route.

Finally, in contrast to Kimura's (1984) findings, Kinoshita and Saito (1992) observed no effect of concurrent articulation for either kanji words or the hiragana transcriptions in their lexical decision experiment. In order to make a correct "word" decision, presumably, a lexical representation would have to be selected. If the lexicalselection process is accomplished directly from orthography for a kanji word but is always mediated by phonology when that kanji word is transcribed into hiragana, as suggested by Kimura, lexical decision performance for the hiragana transcriptions should be selectively disrupted by concurrent articulation.

As a result of the null effect of concurrent articulation for both kanji words and hiragana transcriptions in their experiments, Kinoshita and Saito (1992) suggested an alternative explanation for the greater effect of concurrent articulation for kana transcription pairs in Kimura's (1984) study. In particular, when a kanji word is transcribed into kana, the kana transcriptions tend to be semantically ambiguous because there are a number of homophones among Japanese kanji words, such as 教会 (church, /kjo.uka.i/) and 境界 (boarder, /kjo.u-ka.i/). During the relatedness decisions for kana transcription pairs, therefore, participants would need to maintain the word's phonological code in working memory in order to exhaustively check the relatedness of all the possible meanings. For kanji words, on the other hand, because they are not semantically ambiguous, the decisions would be easier, and there would be no reason to maintain the phonological code for a long period of time. As such, concurrent articulation would disrupt the decisions for the kana transcription pairs much more than those for the kanji word pairs, implying that Kimura's findings cannot be

\footnotetext{
${ }^{4}$ Needless to say, consistency effects in the naming of kanji and katakana words can be explained in terms of parallel distributed processing perspective as well (Fushimi et al., 1999, and Hino et al., 2011, contain detailed accounts of this type).
}

taken as good evidence that the process of retrieving lexical/semantic information is mediated by phonology for kana transcriptions.

\section{The present research}

On the basis of the current literature, therefore, it isn't at all clear whether the nature of the processes involved in reading kana and kanji words are really different, which raises the further question of whether the O-P and O-S consistencies for kana and kanji words are actually different in the first place. That is, the failure to detect a consistency effect in the naming of kanji words in Wydell et al.'s (1995) experiments may be due to the fact that O-P relationships are not necessarily inconsistent for kanji words, even when they consist of kanji characters that have multiple potential pronunciations. At the same time, the consistency effect in the naming of katakana words in Hino et al. (2011) also raises the possibility that the O-P relationships for kana words may not be as consistent as previously assumed. As such, the O-P consistencies for kana and kanji words may not necessarily be as different as previously thought.

Similarly, when considering the relationships between kanji compound words and their constituent kanji characters, the meanings of the compound words are not necessarily predictable from the meanings of their constituents. As noted by Zhou and Marslen-Wilson (2000), although the meanings of English and Chinese compound words are clearly related to the meanings of their constituent morphemes, it is often not possible to predict the meaning of a compound word based on the meanings of its constituents, because the way the constituents contribute to the meaning of the compound word is not always the same. To use an English example, a "snowman" is a man made of snow, but a "mailman" is not a man made of mail. In a similar fashion, the meanings of kanji compound words appear to be unpredictable on the basis of their constituent kanji characters, because the same kanji character is used in different senses in constructing the meanings of different kanji compounds [e.g., 助手 (assistant) and 右手 (right hand), in which the shared kanji character, 手 denotes "a person" and "a hand," respectively]. As a result, kanji words sharing the same character are not necessarily very similar in meaning, and hence, the O-S relationships for kanji words may not really be as consistent as previously assumed.

In the present research, therefore, the goal was to measure the degrees of O-P and O-S consistencies for kana and kanji words in order to examine (1) whether O-P 
relationships truly are more consistent for kana words than for kanji words and (2) whether O-S relationships truly are more consistent for kanji words than for kana words, as previously suggested by a number of researchers (e.g., Feldman \& Turvey, 1980; Frost, 2005; Kimura, 1984; Saito, 1981; Wydell et al., 1995).

\section{Stimulus selection}

Because it would not be possible to measure the O-P and $\mathrm{O}-\mathrm{S}$ consistencies for all existing kana and kanji words, we needed to select representative sets of kana and kanji words for our analysis. In order for the measured consistencies to best reflect the nature of the kana and kanji words in general, we attempted to select kana and kanji words that are as typical as possible. As such, we first examined the characteristics of kana and kanji words in general using the words found in a relatively small computerized Japanese dictionary (National Language Research Institute, 1993) with 36,780 word entries. These word entries were first classified in terms of script type. They included 22,198 kanji words (60.35\%) and 6,548 kana words $(17.80 \%)$. The rest of the word entries consisted of those printed in combinations of kana and kanji characters (7,966 words, $21.66 \%)$ and those involving specific characters from other alphabets (68 words, $0.18 \%)$. When these kana and kanji words were classified in terms of character length, $82.88 \%$ of the kanji words $(18,397$ words) consisted of two kanji characters, whereas $80.39 \%$ of kana words $(5,268$ words $)$ were longer, from three to five characters in length. This difference is due to differences in how morae are represented by kana versus kanji characters. Most Japanese words have three to five morae. For example, when kana and kanji words involved in the familiarity rating norms of Japanese words (Amano \& Kondo, 2003a) were classified in terms of the number of morae, $71.53 \%$ of kana words $(7,571$ out of 10,585 kana words) and $83.17 \%$ of kanji words $(42,859$ out of 51,534 kanji words) consisted of three to five morae. While each kana character corresponds to a single mora, kanji characters generally correspond to multiple morae. As a result, words with three to five morae are generally printed in three to five characters in kana, but they are mostly printed in two characters in kanji. Given this situation, we decided that it would be necessary to use kanji words that are two characters in length and kana words that are three to five characters in length in our analysis.

In order to select the specific stimuli for our analysis, we began by examining nouns from Amano and Kondo's (2003a) syntactic class database. There are
59,850 nouns in the database. These nouns were classified in terms of script type, and then sets of kana words (7,085 words) and kanji words (43,122 words) were selected. In order to further reduce the number of items, we eliminated all of the items that were not listed in the National Language Research Institute's (1970) word frequency norms. Virtually all proper nouns were also eliminated. ${ }^{5}$ In addition, homophones (words having multiple entries sharing the same pronunciation) and homographs (words having multiple entries sharing the same orthographic form) were identified using Amano and Kondo's (2003a) familiarity-rating database, and those words were also eliminated in order to make the computations of the O-P and O-S consistencies as straightforward as possible. As a result, 339 katakana words that were three to five characters in length and 775 kanji words that were two characters in length were selected as stimuli for the present research. ${ }^{6}$

\section{The O-P consistency index}

For these 339 katakana and 775 kanji words, we measured their O-P and O-S consistencies. Because consistency is the degree of transparency or predictability from one domain to the other, in order to measure the O-P and O-S consistencies for a target word, we first needed to collect a group of words that were similar in orthography to the target word. Therefore, we generated orthographic neighbors for each of the 1,114 words using the National Language Research Institute (1993) database. That is, following Coltheart et al. (1977), all of the words generated by changing one character from the target word were listed as orthographic neighbors for each of the 1,114 words.

\footnotetext{
${ }^{5}$ An attempt was made to remove all of the proper nouns. However, because Amano and Kondo's (2003a) syntactic class database does not discriminate common nouns from proper nouns, the removal of proper nouns was based only on the second author's intuition.

${ }^{6}$ National Language Research Institute (1970) lists only words whose word frequency counts are more than 4 per 940,533. As a result, it only contains 13,176 words in total. We used this (relatively small) set of frequency norms because, as will be described later, we needed to reduce the number of items as much as possible in order to conduct subjective ratings (to measure the $\mathrm{O}-\mathrm{S}$ consistencies). We had no qualms about using these norms, because they have been used successfully in the past (e.g., Hino \& Lupker, 1998, reported significant frequency effects in their lexical decision and naming tasks by manipulating frequency based on the National Language Research Institute norms). According to Amano and Kondo (2003b), the frequency counts in their frequency norms are strongly correlated with those in the National Language Research Institute norms $(r=.56)$.
} 
Because the O-P consistency for a word was defined in terms of the degree of similarity in pronunciations for similarly spelled words (orthographic neighbors), we classified the orthographic neighbors as phonological friends or enemies, based on whether or not the shared characters were pronounced the same (at the moraic level) in the target word and the orthographic neighbor (e.g., Fushimi et al., 1999; Jared et al., 1990). After classifying the orthographic neighbors as phonological friends or enemies, we computed the sum of the frequencies of the phonological friends as well as the sum of the frequencies of the phonological enemies using the National Language Research Institute (1970) frequency norms. The word frequency of the target word was added to the summed frequency of the phonological friends, to produce a value that represented the frequency of usage of the charactermora correspondences involved in the target word. In contrast, the summed frequency of phonological enemies was taken to represent the frequency of usage of different character-mora correspondences for the characters involved in the target word.

Using these values, we computed an index of the O-P consistency for each of the 1,114 target words using the following formula:

\section{$\mathrm{O}-\mathrm{P}$ Consistency Index $=($ Target Frequency \\ + Summed Frequency of Phonological Friends)/ (Target Frequency + Summed Frequency of All Neighbors)}

In this formula, the summed frequency of the phonological friends was added to the target frequency, and this value was divided by the value of the summed frequency of all of the neighbors plus the target frequency. This index produces a value between 0 and 1 depending on the degree of O-P consistency. The O-P consistency index should be close to 1 for words with more consistent O-P correspondences, whereas for words with highly inconsistent O-P correspondences, the value should be close to 0 . In addition, as noted above, because we classified the orthographic neighbors as phonological friends or enemies in terms of whether the shared characters between a target word and its neighbors are pronounced the same at the moraic level, the O-P consistency index reflects the nature of character-mora relationships.

\section{The O-S consistency index}

Although the similarity in pronunciations between the target word and its orthographic neighbors could be easily determined in terms of whether or not the shared characters are pronounced the same, it is somewhat more difficult to determine the similarity in meaning between the target word and its orthographic neighbors. In order to estimate the degree of the O-S consistency for each target word, we asked participants to rate the similarity in meaning between the target word and its orthographic neighbors using a 7-point scale, ranging from 1 (very dissimilar) to 7 (very similar). After collecting the ratings, we classified the neighbors as semantic friends if the mean similarity rating was 4.00 or higher. Otherwise, the neighbors were classified as semantic enemies. Then, the summed frequencies of the semantic friends and enemies were calculated in order to compute the O-S consistency index for each of the 1,114 words, using the following formula:

$$
\begin{aligned}
& \mathrm{O}-\mathrm{S} \text { Consistency Index }=(\text { Target Frequency } \\
& + \text { Summed Frequency of Semantic Friends }) / \\
& \quad \text { (Target Frequency }+ \text { Summed Frequency of All } \\
& \text { Neighbors })
\end{aligned}
$$

In this formula, the summed frequency of the semantic friends was added to the target frequency, and this value was divided by the value of the summed frequency of all of the neighbors plus the target frequency. Similar to the O-P consistency index, the O-S consistency index took a value between 0 and 1 . The O-S consistency index should be close to 1 for words with more consistent O-S correspondences, but the value should be close to 0 if the O-S correspondences are highly inconsistent.

By computing the O-P and O-S consistency indices for the 339 katakana and 775 kanji words, we were able to compare these indices between the katakana and kanji words in order to examine (1) whether the O-P consistencies are higher for kana words than for kanji words and (2) whether the O-S consistencies are higher for kanji words than for kana words.

\section{O-P analysis}

\section{Method}

Stimuli and procedure As noted, 339 katakana nouns (3.95 characters in length on average, ranging from three to five characters) and 775 kanji nouns with two characters were selected from Amano and Kondo's (2003a) syntactic class database. The mean numbers of morae were 3.83 for the 339 katakana words and 3.66 for the 775 kanji words. All of these words were non- 
homophonic and nonhomographic according to Amano and Kondo's (2003a) familiarity-rating database and were listed in the National Language Research Institute's (1970) word frequency norms. ${ }^{7}$

For each of the 1,114 words, orthographic neighbors were generated using the National Language Research Institute (1993) database and were classified as phonological friends or enemies, as illustrated in Table 1. Then, the summed frequencies of the phonological friends and enemies were computed using the frequency norms of the National Language Research Institute (1970). When a neighbor was not listed in the norms, the frequency count was assumed to be zero. Based on the target frequency and the summed frequencies of the phonological friends and enemies, the O-P consistency index was computed for each of the 1,114 words.

\section{Results}

The mean O-P consistency indices and the mean summed frequencies of the phonological friends and enemies for the 339 katakana words and the 775 kanji words are shown in Table 2, along with their mean word frequencies and orthographic neighborhood sizes. In addition, the target frequency, orthographic neighborhood size, summed frequency of the phonological friends plus target frequency, summed frequency of the phonological enemies, numbers of phonological friends and enemies, and the O-P consistency indices for each of the 1,114 words are listed in the Appendix. As shown in Table 2, the O-P consistency index was higher for the katakana words (.94) than for the kanji words (.82), a difference that was significant in a one-way ANOVA, $F(1,1112)=65.83$, $M S E=.05, p<.001, \eta^{2}=.056$.

Note, however, that the 1,114 words involved a number of words with no orthographic neighbor listed in National Language Research Institute (1970) frequency norms. Although the computed O-P consistency index is 1.00 for all of these words, the words clearly possess unique spelling patterns and, hence, unique O-P relationships,

\footnotetext{
${ }^{7}$ Mean word lengths, numbers of morae, word frequencies, and orthogrtaphic neighborhood sizes were compared for the 339 katakana words and 775 kanji words. As expected, mean word lengths were significantly greater for the katakana words (3.95) than for the kanji words (2.00), $F(1,1112)=5,175.23, M S E=0.17, p<.001, \eta^{2}=.823$. Mean numbers of morae were also greater for the katakana words (3.83) than for the kanji words $(3.66), F(1,1112)=17.37, M S E=0.36, p<001$, $\eta^{2}=.015$. Mean word frequencies were higher for the kanji words (27.15) than for the katakana words $(18.67), F(1,1112)=7.67, M S E=$ $2,213.46, p<.01, \eta^{2}=.007$, and mean orthographic neighborhood sizes were much higher for the kanji words (47.59) than for the katakana words $(1.77), F(1,1112)=900.80, M S E=549.85, p<.001, \eta^{2}=.448$.
}

much like the so-called "strange" words in English (e.g., Seidenberg, Waters, Barnes, \& Tanenhaus, 1984). Therefore, giving the consistency indices for these words the same weight as those for words that actually have neighbors when calculating mean consistencies may produce a somewhat misleading result. Specifically, doing so may artificially inflate the mean consistency index for both katakana and kanji words.

Note also that, because the number of orthographic neighbors is, in general, negatively correlated with word length (e.g., Forster, Davis, Schoknecht, \& Carter, 1987) and because katakana words were longer than kanji words in our stimulus set, the mean number of orthographic neighbors was significantly smaller for the katakana words (1.77) than for the kanji words (47.59), a difference that was significant in a one-way ANOVA, $F(1,1112)=900.80, M S E=549.85, p<.001, \eta^{2}=.448$. As a result, there were 213 katakana words with no neighbors listed in National Language Research Institute (1970) norms and only 7 kanji words of this sort. Therefore, it's possible that the degree of O-P consistency was overestimated more for the katakana words than for the kanji words in our stimulus set. In order to address this issue, we recomputed the mean O-P consistency indices for the katakana and kanji words after removing the words with unique spelling patterns. The results of that analysis are shown in Table 3. As seen in the table, after removing the 213 katakana words and 7 kanji words with unique spelling patterns, the mean O-P consistency index for katakana words was decreased to .83 (from .94 as shown in Table 2), whereas the mean for the kanji words was unchanged (.82). As a result, the O-P consistency indices were essentially the same for the 126 katakana words (.83) and 768 kanji words (.82), a nonsignificant difference in a one-way ANOVA, $F(1,892)=0.31$, $M S E=.06, \eta^{2}=.000{ }^{8}$

In addition, because there were small correlations between the O-P consistency indices for the 894 words and both target frequency, $r=.088, p<.01$, and orthographic neighborhood size, $r=-.196, p<.001$, we attempted to ascertain whether these factors might have

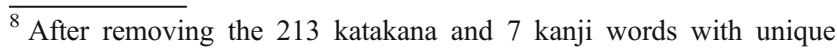
spelling patterns, the mean word lengths were 3.45 for the remaining 126 katakana words and 2.00 for the remaining 768 kanji words, $F(1,892)=4,712.95, M S E=0.05, p<.001, \eta^{2}=.841$. The mean numbers of morae were 3.42 for the katakana words and 3.66 for the kanji words, $F(1,892)=22.43, M S E=0.28, p<.001, \eta^{2}=.025$. The mean word frequencies were 17.81 for the katakana words and 27.15 for the kanji words, $F(1,892)=3.73, M S E=2,531.93, p<.06, \eta^{2}=$ .004 , and the mean orthographic neighborhood sizes were 4.36 for the katakana words and 47.96 for the kanji words, $F(1,892)=306.73$, $M S E=670.84, p<.001, \eta^{2}=.256$.
} 
Table 1 An example of computing the O-P consistency index for a katakana word, ペース (pace, /pe.E.su/)

Target

ペース (pace, /pe.E.su/)

Phonological friends

ケース (case, /ke.E.su/)

ベース (base, /be.E.su/)

レース (race, /re.E.su/)

ページ (page, /pe.E.zi/)

Total

6

20

12

22

36

96
Phonological Enemies

$\begin{array}{ll}\text { アース (earth, /a.A.su/) } & 0 \\ \text { コース (course, /ko.O.su/) } & 66 \\ \text { ソース (source, /so.O.su/) } & 0 \\ \text { ダース (dozen, /da.A.su/) } & 0 \\ \text { ホース (horse, /ho.O.su/) } & 0\end{array}$

66

Orthographic neighbors generated using the National Language Research Institute (1993) database were classified as phonological friends or enemies based on whether the shared characters between the neighbor and target were pronounced the same at the moraic level. The frequency counts were taken from National Language Research Institute (1970). The O-P consistency index of ペース = $96 /(96+66)=.59$

affected our contrast between katakana and kanji words. ${ }^{9}$ To do so, we also conducted a multiple regression analysis on the O-P consistency indices for the 894 words in order to determine whether the script type difference (katakana vs. kanji words) could explain a unique amount of variance in the O-P consistency indices after removing the variance explained by target frequency and orthographic neighborhood size. In this analysis, orthographic neighborhood size, target frequency, and script type were used as predictor variables and entered into the equation in that order, in a stepwise manner. For the script type variable, katakana and kanji words were coded as 0 and 1 , respectively. The regression equation explained a significant amount of variance in the O-P consistency indices, $R^{2}=.055$, $F(3,890)=17.43, M S E=.06, p<.001$. A summary of the results from the regression analysis is shown in Table 4.

As illustrated in Table 4, orthographic neighborhood size was a significant predictor variable, $\beta=-.252$, $t(890)=-6.67, p<.001$, reflecting the fact that the O-P consistency indices decrease for words with more orthographic neighbors. Target frequency was also a significant predictor variable, $\beta=.091, t(890)=2.78, p<.01$, reflecting the fact that the O-P consistency indices were higher for higher-frequency words. In addition, script type

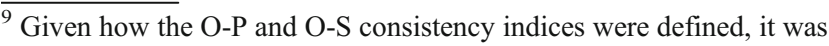
almost inevitable that small correlations of this sort would arise. Target frequency contributes to both the numerator and denominator of the formulas, however, the numerator is, of necessity, a smaller number than the denominator. Therefore, target frequency will contribute relatively more to the numerator than to the denominator, leading to small positive correlations between target frequency and the consistency indices. In contrast, orthographic neighborhood size will contribute more to the denominator than to the numerator, because all of the neighbor frequencies are counted in the denominator total, while only a subset of the neighbor frequencies are counted in the numerator total. As a result, one would expect a small negative correlation between orthographic neighborhood size and the consistency indices.
}

was also a significant predictor variable after the variance explained by the other two variables was removed, $\beta=.103$, $t(890)=2.72, p<.01$. Surprisingly, the $\beta$ for script type was positive, indicating that the O-P consistency index was now higher for the kanji words than for the katakana words. ${ }^{10}$

Finally, because the sample sizes were so dramatically different for the katakana and kanji words in our analyses, we attempted to carry out an analysis involving the same numbers of katakana and kanji words, with the word sets being equated on word frequency and orthographic neighborhood size. A subset of 38 katakana words and 38 kanji words were selected from the 894 words. The mean word frequencies were virtually identical for the katakana words (17.32) and the kanji words (17.50), $F(1,74)=0.00$, $M S E=361.83, \eta^{2}=.000$, as were mean orthographic neighborhood sizes for the katakana words (8.92) and the kanji words $(9.61), F(1,74)=1.78, M S E=5.00, \eta^{2}=.023$. Consistent with the results from the regression analysis, the

\footnotetext{
${ }^{10}$ An identical multiple regression analysis was also conducted for the entire set of the katakana and kanji words. The regression equation explained a significant amount of variance in the O-P consistency indices, $R^{2}=.112, F(3,1110)=46.61, M S E=.05, p<.001$. In addition, both orthographic neighborhood size, $\beta=-.298, t(1110)=-7.84, p<.001$, and target frequency, $\beta=.084, t(1110)=2.97, p<.01$, were significant predictor variables. In contrast, script type was not a significant predictor variable, $\beta=-.044, t(1110)=-1.15$, suggesting that the $\mathrm{O}-\mathrm{P}$ consistency indices were comparable for the katakana and kanji words when the words with unique spelling patterns were included in the analysis.

Note that, as shown in Table 2, the mean word frequencies and orthographic neighborhood sizes were smaller for the 339 katakana words than for the 775 kanji words. Further, the standard deviations of these variables were also smaller for the katakana words than for the kanji words (word frequencies, 26.56 for the katakana words and 53.59 for the kanji words; orthographic neighborhood sizes, 2.94 for the katakana words and 28.04 for the kanji words). As such, the ranges of frequencies and orthographic neighborhood sizes were more limited for the katakana words. As a result, it's possible that it was somewhat more difficult to detect the effects due to these variables on the O-P consistency indices for the katakana words in our regression analyses.
} 
Table 2 Mean word frequency (Freq.), mean orthographic neighborhood size $(N)$, mean O-P consistency index (O-P Index), mean of target frequency plus summed frequency of the phonological friends
(Friends), and mean summed frequency of the phonological enemies (Enemies) for the 339 katakana words and the 775 kanji words

\begin{tabular}{lllllr}
\hline Script type & Freq. & $N$ & O-P index & Friends & Enemies \\
\hline 339 katakana words & 18.67 & 1.77 & .94 & 31.85 & 5.33 \\
775 kanji words & 37.25 & 47.59 & .82 & 481.13 & 120.69 \\
\hline
\end{tabular}

mean O-P consistency index for the kanji words (.88) was significantly higher than that for the katakana words (.70) in a one-way ANOVA, $F(1,74)=7.94, M S E=.08, p<.01$, $\eta^{2}=.097$.

\section{Discussion}

The results of our analysis of the O-P consistencies for the katakana and kanji words indicated that the degrees of O-P consistency were somewhat more comparable for katakana and kanji words than has previously been assumed. In our initial analysis, the mean O-P consistency index was slightly higher for the 339 katakana words than for the 775 kanji words, as shown in Table 2. But because katakana words were longer than kanji words, katakana words generally possessed fewer orthographic neighbors, and as a result our stimulus set involved 213 katakana words, but only 7 kanji words, with unique spelling patterns and, hence, an O-P consistency index of 1.00. Because words having unique spelling patterns have unique relationships between orthography and phonology, as with the "strange" words in English, it may be misleading to conclude that these words actually possess what has been conventionally considered to be consistent O-P relationships. To address this potential issue, we removed these words from our stimulus set and recomputed the mean O-P consistency indices for both katakana and kanji words. With these words removed, the O-P consistency indices were now identical for the 126 katakana and 768 kanji words.

In order to resolve another potentially important issue, the potential confound with target frequency and orthographic neighborhood size, we conducted a regression analysis in which the factors target frequency and orthographic neighborhood size were included as predictors along with script type. When the variance explained by target frequency and orthographic neighborhood size was

Table 3 Mean word frequency (Freq.), mean orthographic neighborhood size $(N)$, mean O-P consistency index (O-P Index), mean of target frequency plus summed frequency of the phonological friends removed, the O-P consistency indices were actually higher for kanji words than for katakana words. Similar results were also observed in the ANOVA using the 38 katakana and 38 kanji words having equivalent word frequencies and orthographic neighborhood sizes.

The upshot of these analyses is that the O-P consistencies were actually quite comparable for the katakana and kanji words. What is likely to seem most surprising about these results would be that our set of katakana words would actually have a consistency index less than 1.00 (i.e., this fact might seem more surprising than the fact that kanji words are actually fairly consistent once context - that is, the other constituent character in the word-is taken into account). Kana words have been assumed to have highly consistent O-P relationships; however, what the present results document is that that assumption is actually incorrect. In particular, katakana words with macrons possess inconsistent O-P relationships. The macron, which is a quite common character, is a dash-like character [e.g., the — in ソース (source, /so.O.su/)] that denotes that the vowel involved in the previous character is a prolonged ("long") vowel. Combining the macron with the previous katakana character, therefore, creates a single syllable with a long vowel (i.e., a /CVV/ syllable). That is, the longvowel syllable (which has two morae, /CV/ and /V/) has a duration twice as long as a syllable with a single mora, with a macron being pronounced the same as the vowel involved in the previous katakana character. Because there are five different vowels in Japanese phonology (e.g., /a/, /e/, /i/, /o/, and $/ \mathrm{u} /$ ), a macron has five different possible pronunciations at the moraic level. Hence, katakana words with macrons clearly involve inconsistent character-mora relationships.

Although Tamaoka and Terao (2004) suggested that the syllabic units play a major role and the moraic units play essentially no role in the naming of kana-written strings, as

\begin{tabular}{llllll}
\hline Script type & Freq. & $N$ & O-P index & Friends & Enemies \\
\hline 126 katakana words & 17.81 & 4.36 & .83 & 53.23 & 14.34 \\
768 kanji words & 27.15 & 47.96 & .82 & 485.27 & 121.79 \\
\hline
\end{tabular}

(Friends), and mean summed frequency of the phonological enemies (Enemies) for the 126 katakana words and the 768 kanji words after removing the words with unique spelling patterns 
Table 4 Summary of the results from the multiple regression analysis on the O-P consistency indices for the 126 katakana and 786 kanji words

\begin{tabular}{lll}
\hline Predictor variable & $\beta$ & $t$ \\
\hline Orthographic neighborhood size & -.252 & $-6.67^{* *}$ \\
Target frequency & .091 & $2.78^{*}$ \\
Script type (katakana $=0$, kanji $=1)$ & .103 & $2.72^{*}$ \\
\hline
\end{tabular}

$d f=890 .{ }^{*} p<.01 .{ }^{* *} p<.001$

previously noted, Hino et al. (2011) reported a significant effect of character-mora consistency in the naming of katakana words when examining words containing macrons. Hino et al.'s findings in their naming task, as well as the results of our analysis, indicate that the O-P relationships (i.e., character-mora relationships) for kana words are actually less consistent than previously assumed.

Our results also suggest, of course, that the O-P relationships for kanji words are more consistent than previously assumed. Although most kanji characters correspond to multiple pronunciations, what our results show is that when each character is used in a specific position in compound words, it tends to be pronounced the same. This analysis provides a reasonable explanation of Wydell et al.'s (1995) results. As previously noted, Wydell et al. failed to observe a consistency effect in the naming of kanji words when O-P consistency was manipulated based on the number of pronunciations possessed by the constituent characters. Because there is a strong tendency for each kanji character to be pronounced the same when it is used in a specific position in the word, O-P consistency was not strongly manipulated in Wydell et al.'s experiments.

For the present purposes, however, the point is that our results indicate that the O-P consistencies are quite comparable for kana and kanji words. Based on our results, therefore, it becomes somewhat harder to make the argument that there are processing differences in the phonological coding of kana and kanji words due to differences in the nature of the relationships between orthography and phonology.

\section{O-S analysis}

The next issue to be addressed is the question of the O-S consistencies for kana and kanji words. In particular, we attempted to evaluate whether the O-S relationships really are more consistent for kanji than for kana words.

\section{Method}

Participants A total of 876 undergraduate and graduate students from Waseda University participated in this study in exchange for a small amount of money ( $¥ 500$ ). All of the students were native Japanese speakers.

Stimuli For each of the 339 katakana and 775 kanji words used in the analysis of the O-P consistencies, orthographic neighbors were generated using the National Language Research Institute (1993) database, and each of the neighbors was paired with the target word only if it was listed in the frequency norms of National Language Research Institute (1970). This procedure was employed to reduce the number of word pairs used in the subjective ratings. Nonetheless, 12,407 word pairs were created with this procedure. The 12,407 word pairs were then randomly divided into 31 sets of word pairs, each of which consisted of either 400 or 401 word pairs. Based on the 31 sets of word pairs, 31 versions of a questionnaire were created. In each questionnaire, the instructions to the participants were printed on the first page. Starting on the second page, word pairs were randomly ordered and printed with a 7-point scale ranging from 1 (very dissimilar) to 7 (very similar). The rating scale was printed below each word pair. Because 32 word pairs were printed on one page, each questionnaire consisted of 14 pages in total.

Procedure The data collection was conducted in groups in a normally lit room. A group of participants was gathered in the room, and an experimenter handed a pencil and a questionnaire to each of the participants. At the front of the room, the experimenter read aloud the instructions printed on the first page of the questionnaire. That is, the experimenter asked participants to rate the similarity in meanings for each of the word pairs printed in the questionnaire by circling the appropriate number on the scale. The participants were also instructed (1) to use the entire scale in their ratings, (2) to be consistent in their use of the scale across all of the word pairs, (3) to quickly preview all of the word pairs in order to get an idea of their range, and (4) to be careful not to skip any of the pairs. At least 27 participants were assigned to each version of the questionnaire. The entire session took about $30 \mathrm{~min}^{11}$

\section{Results}

After collecting the 876 participants' rating data, mean ratings were computed for all of the 12,407 word pairs. Based on the mean ratings, orthographic neighbors of each

\footnotetext{
${ }^{11}$ For 10 versions of questionnaire, there were 27 participants assigned to each version. A total of 28 participants were assigned to each of another 10 versions, 29 participants to each of a further 5 versions, and 30 participants to each of another 5 versions. Finally, 31 participants were assigned to 1 version.
} 
of the 1,114 words were classified as semantic friends or enemies. An orthographic neighbor was classified as a semantic friend if the mean rating of the target-neighbor pair was greater than or equal to 4.00. Otherwise, the orthographic neighbor was classified as a semantic enemy. After classifying the orthographic neighbors, summed frequencies of semantic friends and enemies were computed using the National Language Research Institute (1970) frequency norms, and an O-S consistency index was computed for each of the 1,114 words. Table 5 illustrates an example of computing the O-S consistency index for the kanji word 簡素 (simple).

The mean O-S consistency indices and the mean summed frequencies of the semantic friends and enemies for the 339 katakana words and the 775 kanji words are shown in Table 6, along with their mean word frequencies and orthographic neighborhood sizes. The summed frequency of the semantic friends plus the target frequency, the summed frequency of the semantic enemies, the numbers of semantic friends and enemies (involving only those that were listed in National Language Research Institute, 1970), and the O-S consistency indices for each of the 1,114 words are also listed in Appendix. In contrast to the predictions, as shown in Table 6, the O-S consistency index was actually higher for the katakana words (.76) than for the kanji words (.26), a difference that was highly significant in a one-way ANOVA, $F(1,1112)=689.73, M S E=.08, p<.001$, $\eta^{2}=.383$.

As with O-P consistency, however, it was possible that the degree of O-S consistency was overestimated more for the katakana words than for the kanji words because the katakana word set involved more words with unique spelling patterns (as previously noted, there were 213 katakana and 7 kanji words of this sort). As with the O-P consistency index, the O-S consistency index will result in a value of 1.00 when there is no orthographic neighbor listed in the frequency norms. Therefore, once again we removed the 213 katakana and 7 kanji words with unique spelling patterns and recomputed the mean O-S consistency indices for the remaining 126 katakana and 768 kanji words. The results are shown in Table 7 . As can be seen in that table, after removing the 220 words with unique spelling patterns, the O-S consistency indices were still higher for the 126 katakana words (.34) than for the 768 kanji words (.25), a difference that was, once again, significant in a one-way ANOVA, $F(1,892)=14.31$, $M S E=.06, p<.001, \eta^{2}=.016$.

In addition, as with the O-P consistency indices, the O-S consistency indices for the 894 words were positively correlated with target frequency, $r=.244, p<.001$, and negatively correlated with orthographic neighborhood size, $r=-.419, p<.001$. To address concerns raised by this issue, we conducted a multiple regression analysis on the O-S consistency indices for the 894 words in order to determine whether the script type difference (katakana vs. kanji words) could explain a unique amount of variance in the O-S consistency indices after removing the variance explained by target frequency and orthographic neighborhood size. Similar to the regression analysis on the O-P consistency indices, katakana and kanji words were coded as 0 and 1 , respectively, for script type, which was used as a predictor variable, together with target frequency and orthographic neighborhood size. These predictor variables were, then, entered into the regression equation in a stepwise manner, just as in the analysis of the O-P consistency indices. The regression equation explained a significant amount of variance in the O-S consistency indices, $R^{2}=.251, F(3,890)=99.52, M S E=.05, p<.001$. A summary of the results from the regression analysis is shown in Table 8.

Table 5 An example of computing the O-S consistency index for a kanji word, 簡素 (simple, /ka. $N$-so/)

\begin{tabular}{|c|c|c|c|c|c|}
\hline & Rating & Frequency & & Rating & Frequency \\
\hline \multicolumn{6}{|l|}{ Target } \\
\hline 簡素 (simple) & & 5 & & & \\
\hline Semantic Friends & & & Semantic Enemies & & \\
\hline 簡易 (simple) & 6.28 & 15 & 要素 (element) & 2.21 & 20 \\
\hline \multirow[t]{4}{*}{ 簡単 (easy) } & 5.78 & 46 & 炭素 (carbon) & 1.29 & 8 \\
\hline & & & 酵素 (enzyme) & 1.25 & 9 \\
\hline & & & 酸素 (oxygen) & 1.13 & 39 \\
\hline & & & 水素 (hydrogen) & 1.07 & 9 \\
\hline Total & & 66 & & & 85 \\
\hline
\end{tabular}

Orthographic neighbors generated using the National Language Research Institute (1993) database were classified as semantic friends or enemies based on the mean similarity ratings for the target-neighbor pairs. The frequency counts were taken from National Language Research Institute (1970). The O-S consistency index of 簡素 $=66 /(66+85)=.44$ 
Table 6 Mean word frequency (Freq.), mean orthographic neighborhood size $(N)$, mean O-S consistency index (O-S Index), mean of target frequency plus summed frequency of the semantic friends
(Friends), and mean summed frequency of the semantic enemies (Enemies) for the 339 katakana words and the 775 kanji words

\begin{tabular}{lllll}
\hline Script type & Freq. & $N$ & O-S index & Friends \\
\hline 339 katakana words & 18.67 & 1.77 & .76 & 18.74 \\
775 kanji words & 37.25 & 47.59 & .26 & 108.78 \\
\hline
\end{tabular}

As illustrated in Table 8, orthographic neighborhood size was a significant predictor variable, $\beta=-.480$, $t(890)=-14.27, p<.001$, reflecting the fact that the $\mathrm{O}-\mathrm{S}$ consistency indices were lower for words with more orthographic neighbors. Target frequency was also a significant predictor variable, $\beta=.256, t(890)=8.81$, $p<.001$, reflecting the fact that the $\mathrm{O}-\mathrm{S}$ consistency indices were higher for higher-frequency words. In addition, script type was a significant predictor variable when the variance explained by the other two variables was removed, $\beta=.101, t(890)=2.99, p<.01$. Because the $\beta$ for script type was positive, the results suggested that the O-S consistency indices were now higher for the kanji words than for the katakana words. Thus, when the impacts of both word frequency and orthographic neighborhood size were removed for the katakana and kanji words, the O-S consistency indices were higher for the kanji than for the katakana words. ${ }^{12}$

Finally, as in the analyses of the O-P consistency indices, we also compared the O-S consistency indices for the 38 katakana and 38 kanji words that were selected in the O-P analysis using a one-way ANOVA. For these words, the mean O-S consistencies were significantly higher for the kanji words (.50) than for the katakana words (.17), $F(1,74)=30.69, M S E=.07, p<.001, \eta^{2}=.293$. As such, consistent with the results from the regression analysis, the O-S consistencies were higher for the kanji than for the katakana words when target frequency and orthographic neighborhood size were equated for katakana and kanji words.

\footnotetext{
$\overline{12}$ An identical multiple regression analysis was also conducted for the entire set of the katakana and kanji words. This equation explained a significant amount of variance in the O-S consistency indices, $R^{2}=$ $.492, F(3,1110)=358.62, M S E=.07, p<.001$. Further, both orthographic neighborhood size, $\beta=-.395, t(1110)=-13.74$, $p<.001$, and target frequency, $\beta=.154, t(1110)=7.17, p<.001$, were significant predictor variables. In addition, script type was also a significant predictor variable, $\beta=-.367, t(1110)=-12.73, p<.001$. Because all of the words with unique spelling patterns were involved in this analysis, the $\beta$ for script type was negative, indicating that the $\mathrm{O}-\mathrm{S}$ consistency indices were higher for the katakana than for the kanji words.
}

\section{Discussion}

In order to examine whether the O-S consistencies are higher for kanji words than for kana words, we attempted to measure the O-S consistencies for 339 katakana and 775 kanji words. As shown in Table 6, the O-S consistency indices for these words were higher for the katakana words than for the kanji words. Because the katakana words were longer than the kanji words, the number of orthographic neighbors was smaller for the katakana words (1.77) than for the kanji words (47.59). As a result, there were many more katakana words than kanji words that had no orthographic neighbor listed in the word frequency norms. According to the formula used to compute the O-S consistency index, that index was always 1.00 for these words. Because these words are considered to have unique spelling patterns and unique O-S relationships, one could argue that giving those words the same weight as words with neighbors when calculating mean $\mathrm{O}-\mathrm{S}$ consistencies tends to artificially inflate the calculated means.

In order to examine this issue more closely, we recomputed the mean $\mathrm{O}-\mathrm{S}$ consistency indices for the katakana and kanji words after removing the words with unique spelling patterns. Even when the words of this sort were removed, however, the O-S consistency indices were still significantly higher for the 126 katakana words (.34) than for the 768 kanji words (.25).

Only when the variance explained by target frequency and orthographic neighborhood size was removed in a regression analysis were the $\mathrm{O}-\mathrm{S}$ consistency indices higher for the kanji than for the katakana words. Similar results emerged in an ANOVA in which target frequency and orthographic neighborhood size were equated for 38 katakana and 38 kanji words. Both of these analyses demonstrate that the $\mathrm{O}-\mathrm{S}$ consistency index is strongly modulated by the orthographic neighborhood size of a word, even after removing the words with unique spelling patterns. Regardless of script type, when a word has more orthographic neighbors, almost by necessity, it increases the probability of having semantic enemies in the orthographic neighborhood. Such would more likely be true for katakana words, because katakana characters are phonetic in nature, 
Table 7 Mean word frequency (Freq.), mean orthographic neighborhood size $(N)$, mean O-S consistency index (O-S Index), mean of target frequency plus summed frequency of the semantic friends
(Friends), and mean summed frequency of the semantic enemies (Enemies) for the 126 katakana words and the 768 kanji words after removing the words with unique spelling patterns

\begin{tabular}{llllll}
\hline Script type & Freq. & $N$ & O-S index & Friends & Enemies \\
\hline 126 katakana words & 17.81 & 4.36 & .34 & 18.01 & 49.57 \\
768 kanji words & 27.15 & 47.96 & .25 & 109.52 & 497.34 \\
\hline
\end{tabular}

and there is no reason to expect that words sharing the same katakana characters will also share meanings [e.g., ポケット (pocket) and ロケット (rocket)]. As a result, katakana words with more orthographic neighbors would tend to have more semantic enemies and, hence, less consistent O-S relationships.

For kanji words, on the other hand, it had been expected that words having the same kanji characters would tend to have similar meanings, because kanji characters are morphemes. According to our data, however, this expectation receives only limited support. Rather, as discussed by Zhou and Marslen-Wilson (2000), the meaning of a compound word does not appear to always be transparent and predictable from the meanings of its constituent morphemes, not only in English and Chinese, but also with Japanese kanji words. As a result, for words written in either script, the probability of having semantic enemies was not small, and the O-S relationships were less consistent when there were more orthographic neighbors. This tendency does appear to be somewhat weaker for kanji words than for katakana words, however. Thus, when the variance explained by orthographic neighborhood size and target frequency was removed in the regression analysis (and when these two variables were equated as much as possible in the word sets used in the ANOVA), the O-S consistency indices were higher for kanji than for katakana words.

What is also clear, however, based on our results, is that the conclusion that the O-S relationships are more consistent for kanji than for kana words is, at best, a weak one. Rather, because kanji words are generally shorter than kana words and because the numbers of orthographic neighbors are also generally larger for kanji words than for kana words, kanji words generally possess numerous semantic enemies, and hence, the potential advantage in O-S consistencies for kanji words due to their morphemic structure appears to be, to a large extent, negated. Therefore, a reasonable conclusion from these results would be that, in contrast to what has been previously assumed, the O-S relationships appear to be reasonably similar for kana and kanji words.

\section{General discussion}

On the basis of the assumption that Japanese kana and kanji words possess qualitatively different relationships between orthography and phonology, the suggestion has been made that the nature of the phonological-coding process is also different for kana than for kanji words. In particular, according to a position that follows from the orthographic depth hypothesis (see, e.g., Frost, 2005; Frost et al., 1987), because the O-P relationships are quite transparent for kana-written words, kana words are assumed to be named only via assembly-type processes (e.g., Kimura, 1984; Morton \& Sasanuma, 1984; Saito, 1981). In contrast, because kanji characters generally possess multiple pronunciations (e.g., on-reading and kun-reading pronunciations), the O-P relationships are considered to be fairly complicated for kanji words. As a result, kanji words are assumed to always be named as a result of processing on a lexical route (e.g., Kimura, 1984; Saito, 1981; Wydell et al., 1995).

According to this theoretical position, the nature of the semantic-coding process is also assumed to be different for kana and kanji words. Because kanji characters carry meaning (i.e., morphemes), words sharing the same kanji characters are expected to have similar meanings. In contrast, because kana characters are phonetic, there is no reason to expect that words sharing the same kana characters will also share meanings. If so, the relationships between orthography and semantics should be more consistent for kanji words than for kana words. Based on these assumptions, therefore, lexical/seman-

Table 8 Summary of the results from the multiple regression analysis on the O-S consistency indices for the 126 katakana and 786 kanji words

\begin{tabular}{lll}
\hline Predictor variable & $\beta$ & $t$ \\
\hline Orthographic neighborhood size & -.480 & $-14.27^{* *}$ \\
Target frequency & .256 & $8.81^{* *}$ \\
Script type (katakana $=0$, kanji $=1)$ & .101 & $2.98^{*}$ \\
\hline$d f=890 .{ }^{*} p<.01 .{ }^{* *} p<.001$ & &
\end{tabular}


tic coding has been assumed to be carried out based directly on orthography for kanji words but to always be mediated by phonology for kana words (e.g., Kimura, 1984; Saito, 1981).

More recent empirical findings have appeared to challenge this theoretical position. For example, word frequency and familiarity effects have been reported in the naming not only of kanji words but also of kana words (e.g., Besner \& Hildebrandt, 1987; Hino \& Lupker, 1998). Some semantic effects have also been reported in the naming of both kanji words (e.g., Hino et al., 2002; Shibahara et al., 2003) and kana words (e.g., Hino et al., 1998). Further, print-sound consistency effects have also been reported in the naming of both kanji words (e.g., Fushimi et al., 1999) and kana words (e.g., Hino et al., 2011). In contrast to the position based on the orthographic depth hypothesis, all of these findings suggest lexical/semantic involvement in the naming of both kanji and kana words and, hence, suggest that the phonological-coding processes may be rather more similar in nature for kanji and for kana words than has previously been thought.

Consistent with the original assumption that lexical/ semantic coding is carried out directly from orthography for kanji words but is always mediated by phonology for kana-written words, Kimura (1984) reported that performance in a relatedness judgment task was more disrupted by concurrent articulation for hiragana transcription pairs than for the original kanji word pairs. Using a lexical decision task, however, Kinoshita and Saito (1992) reported no effect of concurrent articulation for either the original kanji words or their hiragana transcriptions. Further, because the larger effect of concurrent articulation for the hiragana transcription pairs in Kimura's study could be accounted for in terms of the increased semantic ambiguity for hiragana transcription pairs, it is not at all clear that Kimura's data have much to say about the nature of lexical/semantic coding differences for kana and kanji words.

The bulk of the evidence, therefore, seems to indicate that the nature of the processes involved in phonological coding and lexical/semantic coding are actually somewhat similar for kana and kanji words, with the present findings raising the question of whether the O-P and O-S relationships themselves are really different for kana and kanji words. Wydell et al. (1995), for example, failed to observe a consistency effect in the naming of kanji words when consistency was manipulated by considering the number of possible pronunciations possessed by the constituent kanji characters. Given the fact that a consistency effect does arise in the naming of kanji words when consistency is manipulated using orthographic neighbors (e.g., Fushimi et al., 1999), Wydell et al.'s results appear to reflect the tendency for a kanji character to be pronounced the same whenever it is used in a specific character position. This fact alone would indicate that the O-P relationships for kanji words are more consistent than previously assumed. In addition, because the meaning of a compound word is not always transparent and predictable from the meanings of its constituent morphemes (e.g., Zhou \& MarslenWilson, 2000), it is not necessarily the case that words sharing the same kanji characters are inevitably similar in meaning. As such, the O-S relationships for kanji words appear to be somewhat less consistent than previously thought.

\section{O-P consistencies and the nature of phonological coding for kana and kanji words}

In our analysis of the O-P consistencies for 339 katakana words and 775 kanji words, the results clearly indicated that the O-P consistencies were fairly high not only for the katakana words (.94), but also for the kanji words (.82). Equally importantly, when words with unique spelling patterns were removed from the stimulus set, the O-P consistency indices were comparable for the katakana (.83) and kanji words (.82). Further, when the variance explained by target frequency and orthographic neighborhood size was removed using a regression analysis (and when these variables were equated by selecting the small set of katakana and kanji words analyzed with an ANOVA), the O-P consistency index was actually higher for the kanji words than for the katakana words.

These results clearly indicate that, in contrast to what had been previously assumed (e.g., Kimura, 1984; Morton \& Sasanuma, 1984; Saito, 1981; Wydell et al., 1995), O-P consistencies are fairly comparable for kana and kanji words. Our results, therefore, suggest that it is not at all unreasonable to assume qualitatively similar processes in the naming of kana and kanji words, a position consistent with more recent findings (e.g., Besner \& Hildebrandt, 1987; Fushimi et al., 1999; Hino et al., 2011; Hino \& Lupker, 1998; Hino et al., 2002; Hino et al., 1998; Shibahara et al., 2003).

When comparing pronunciations of shared kanji characters across orthographic neighbors, there are some cases in which the constituent kanji character is pronounced differently not because the same character is assigned to different types of pronunciations [e.g., on-reading vs. kunreading pronunciations such as 食品 (food, /sjo.ku-hi.N/) vs. 手品 (magic, /te-zi.na/)] but because a phonemic alternation occurs at the morphemic boundary [e.g., 食品 (food, /sjo.ku$h i . N /$ ) vs. 新品 (something new, /si.N-pi.N/)]. In our analysis, we always classified phonemic alternations as different pronunciations. One may argue, however, that this 
classification is somewhat misleading, because the two characters still share the same type of the pronunciation.

If, instead, we had classified the phonemic alternations as the same pronunciation, the phonological enemies created by the phonemic alternations would have been classified as phonological friends. Hence, the O-P consistency indices for kanji words would have been even higher. In contrast, because most of our katakana words were monomorphemic and because they would be spelled differently whenever a phonemic alternation occurred, the orthographic neighbors for katakana words would not involve phonemic alteration. As such, even if phonemic alternations had been classified as the same pronunciations for kanji words, our general conclusion would be essentially the same. That is, both katakana and kanji words possess highly consistent and reasonably comparable O-P relationships.

\section{O-S consistencies and the nature of lexical/semantic coding for kana and kanji words}

In our analysis of O-S consistencies, we measured the similarity in meanings between the target word and its orthographic neighbors, allowing us to classify the orthographic neighbors as semantic friends or enemies and then to compute an $\mathrm{O}-\mathrm{S}$ consistency index. Inconsistent with the prediction from the position based on the orthographic depth hypothesis, the computed O-S consistency index was higher for the 339 katakana words (.76) than for the 775 kanji words (.26). Further, when words with unique spelling patterns were removed from the stimulus set, the O-S consistency index was still higher for the katakana words (.34) than for the kanji words (.25). An advantage due to the morphemic structure of kanji words was observed in the regression analysis and in the ANOVA involving a small set of matched items, however. That is, the O-S consistency indices were higher for the kanji words than for the katakana words in the regression analysis when the variance explained by target frequency and orthographic neighborhood size on the O-S consistency indices was removed, and in the ANOVA when these two variables were equated for 38 katakana and 38 kanji words. Based on our results, therefore, it does not appear, to any large degree, that the O-S relationships are noticeably more consistent for kanji words than for kana words.

Together with other empirical findings (e.g., Kinoshita \& Saito, 1992), our results therefore appear to provide a challenge to the position based on the orthographic depth hypothesis, in which lexical/semantic coding is assumed to be carried out directly from orthography for kanji words but to be mediated by phonology for kana words. That is, given the similar O-S and O-P consistencies for kana and kanji words, there would be no reasonable basis for assuming processing differences during lexical/semantic coding as a function of script type.

There are, of course, a number of other characteristics that do seem to be different for kana and kanji words-for example, their morphemic structure. Thus, it is possible that there truly are some qualitatively different aspects of the processing of kana and kanji words, because of those other characteristics that differ between them. For example, assuming that polymorphemic words are, initially, analyzed into the morpheme-level representations and then integrated into a single, whole-word representation, as suggested by Taft $(2003$, 2004), it may be the case that morphemic processing always takes place when reading kanji compound words.

Note, however, that there are some polymorphemic kana words in Japanese as well [e.g., フライパン (/fu.ra. i-pa.N/, frying pan) and ホームラン (/ho.O.mu-ra.N/, home run)]. Therefore, it is not clear that kanji and kana words actually differ qualitatively on this dimension, either. Although this issue is beyond the scope of the present research, future research will need to address the issue of morphology in order to provide a better understanding of the characteristics of Japanese kana and kanji words, as well as the nature of the processes involved in the reading of those words.

Author Note This research was supported by JSPS KAKENHI (19530667).

\section{Appendix: List of 339 kana and 775 kanji words used in the present research}

Character length (Len), number of morae (Morae), word frequency (Freq.), orthographic neighborhood size $(\mathrm{N})$, summed frequency of phonological friends plus target frequency $\left(\mathrm{PF} \_\mathrm{F}\right)$, summed frequency of phonological enemies (PE_F), number of phonological friends (PF_N), number of phonological enemies (PE_N), O-P consistency index (O-P Index), summed frequency of semantic friends plus target frequency (SF_F), summed frequency of smantic enemies (SE_F), number of semantic friends (SF_N), number of semantic enemies (SE_N), and O-S consistency index (O-S Index) for 339 katakana and 775 kanji words, along with their English translations. See the text and table note at the bottom of Appendix for more details. 


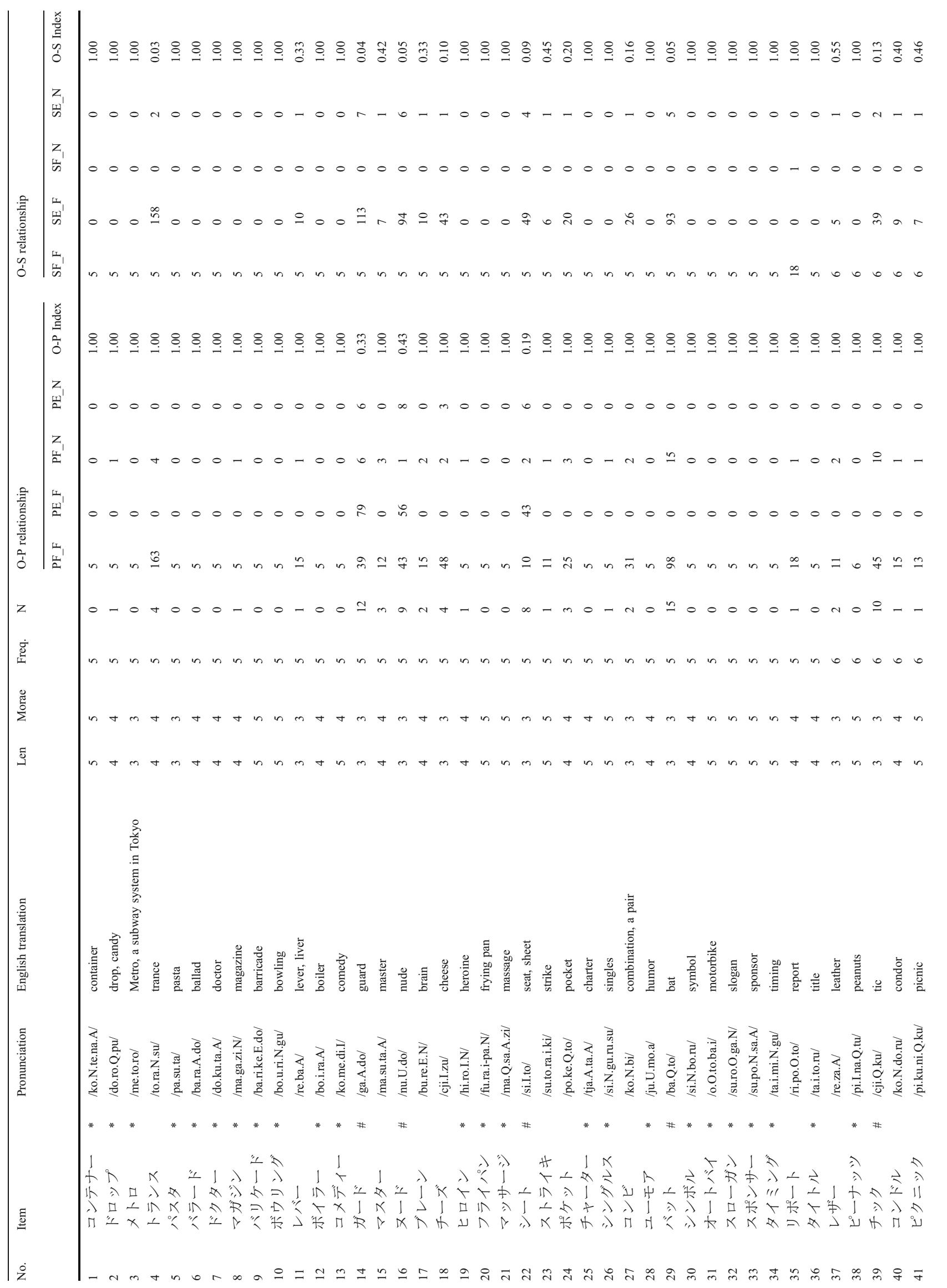




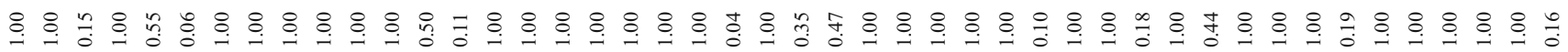

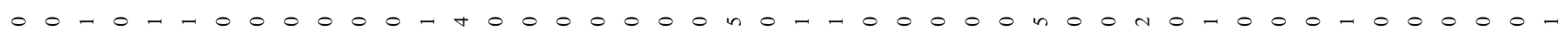
000000000000000000000000000000000000000000000

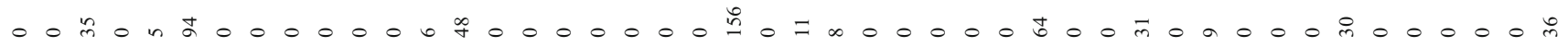

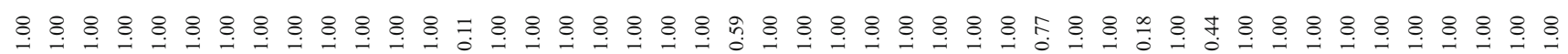

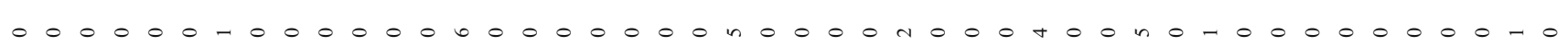

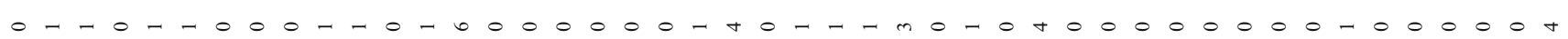

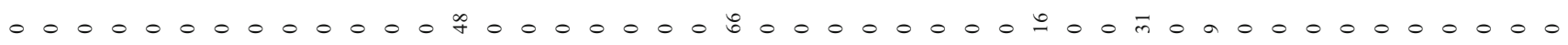

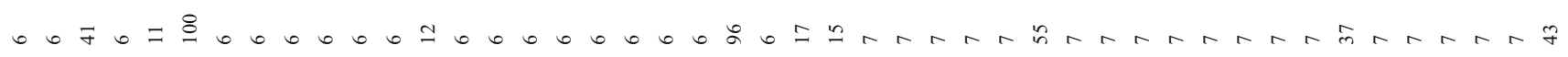
o- -

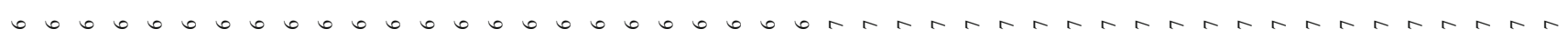

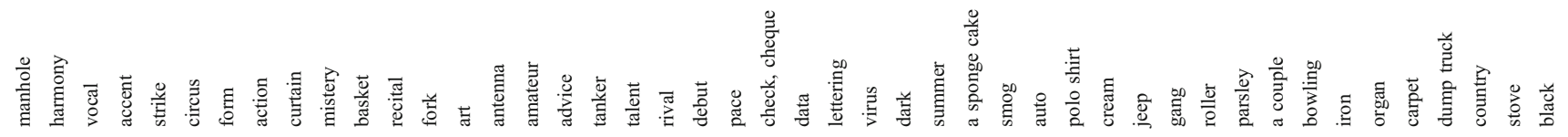

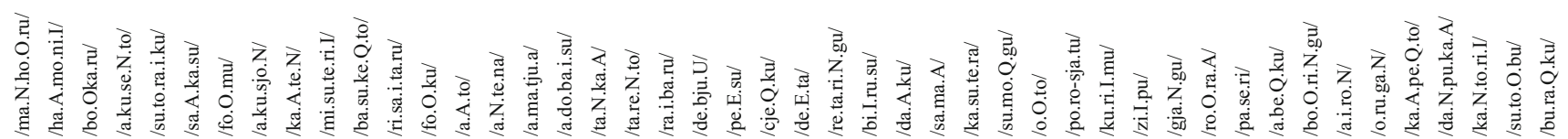

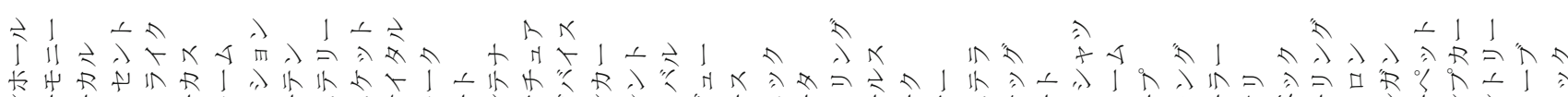

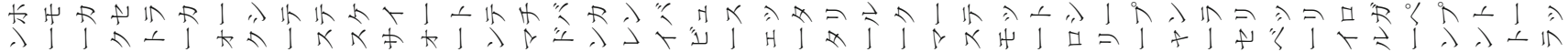

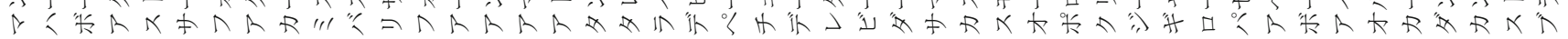

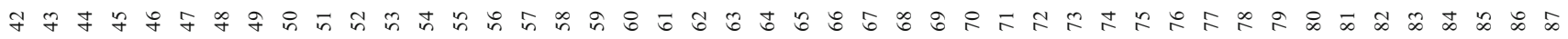




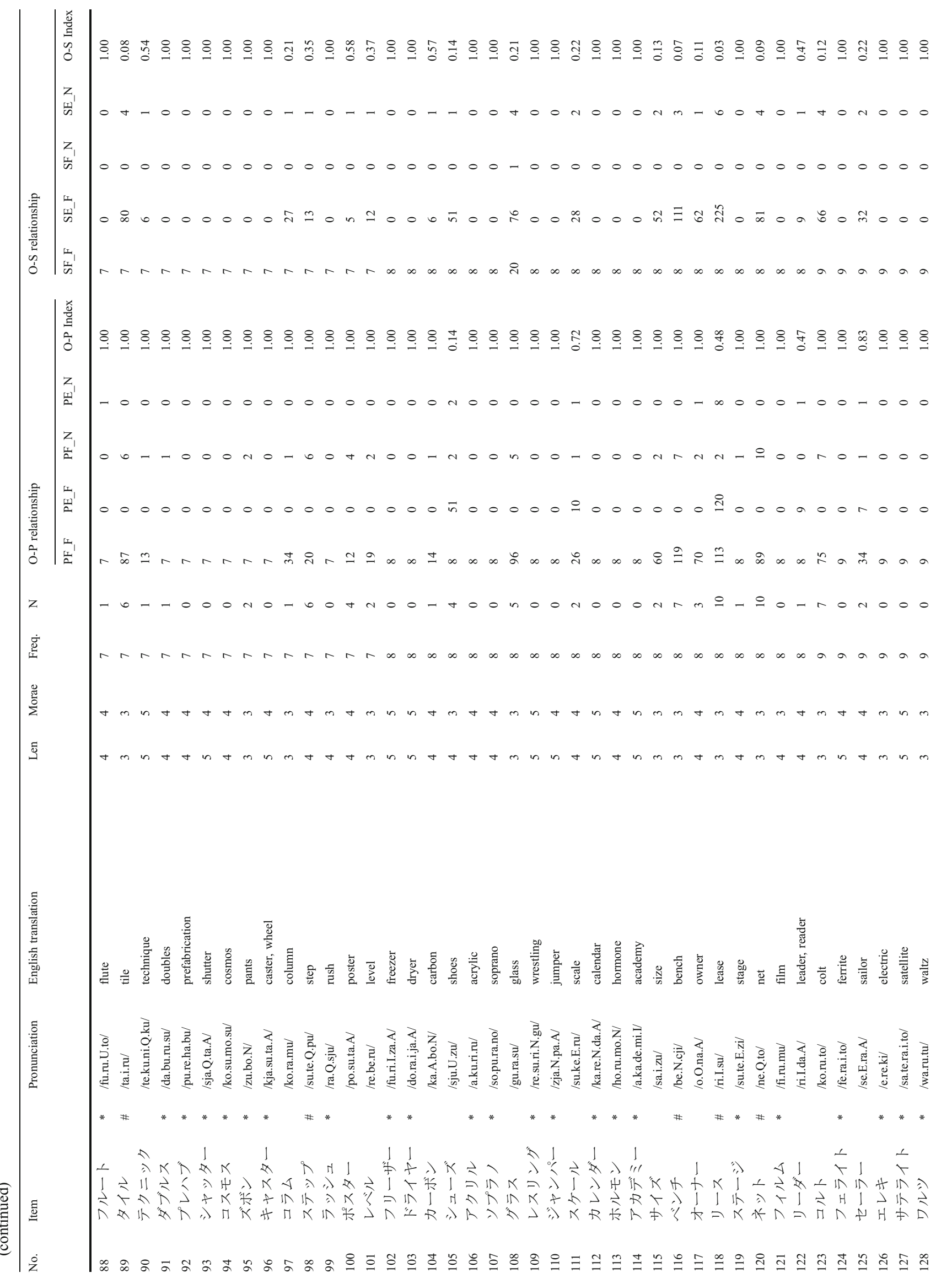


$\stackrel{\leftrightarrow}{\circ}$ \&

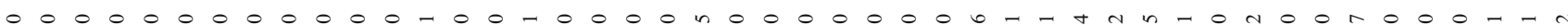

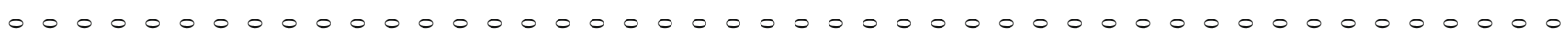

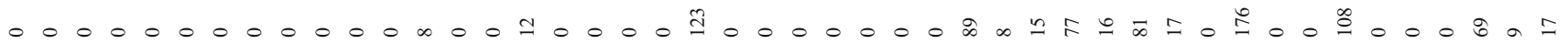

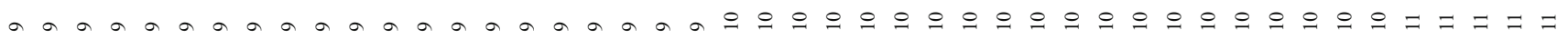
$\stackrel{\leftrightarrow}{\circ}$ \&

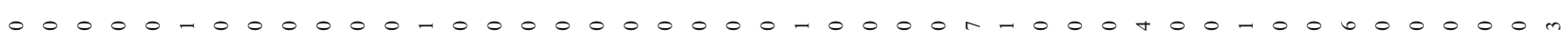

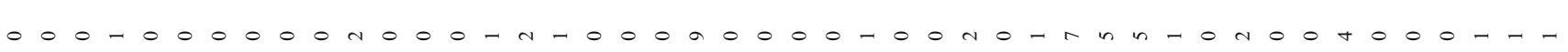

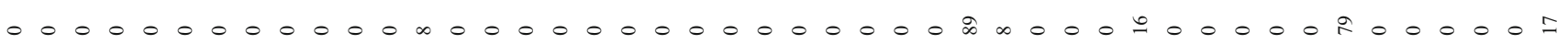

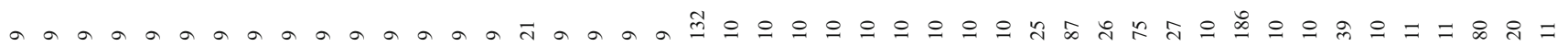

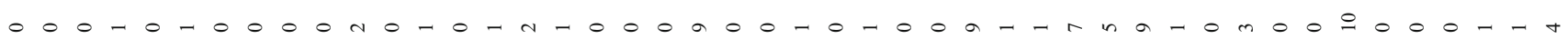

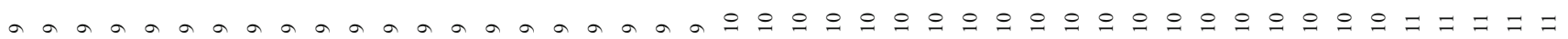

Mhinhly

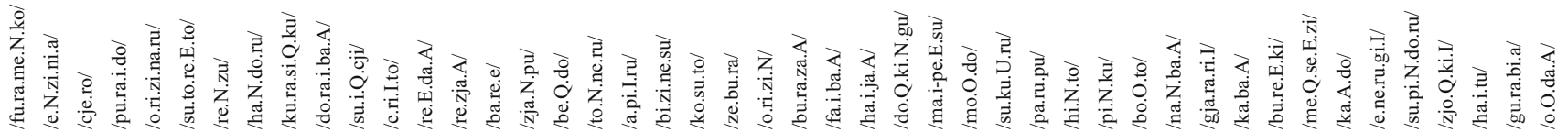

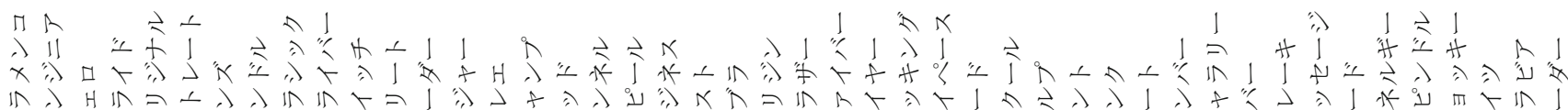

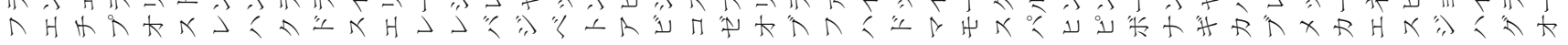

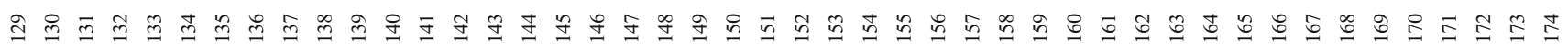




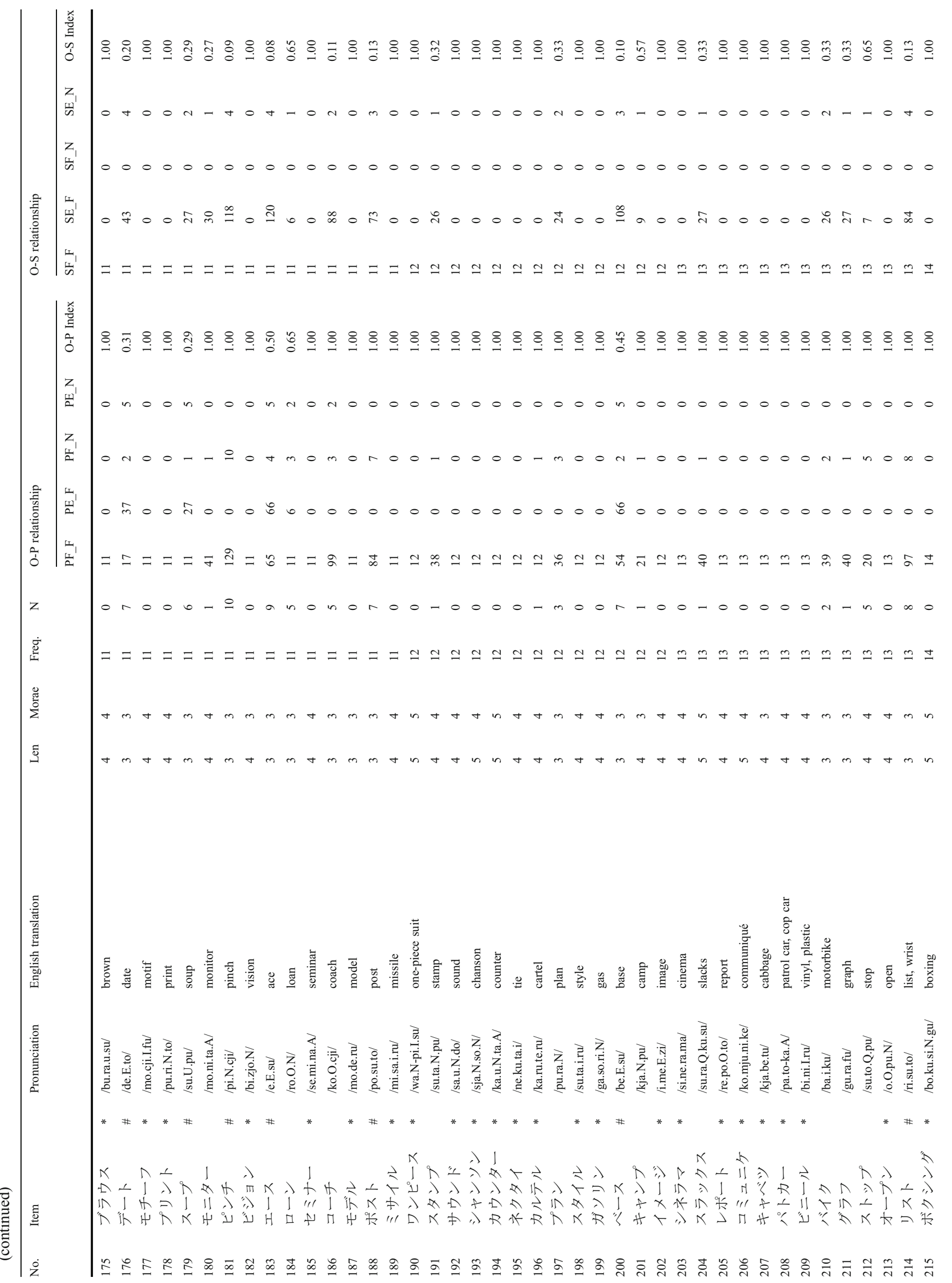


\&

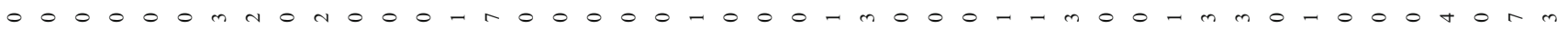
000000000000000000000000000000000000000000000

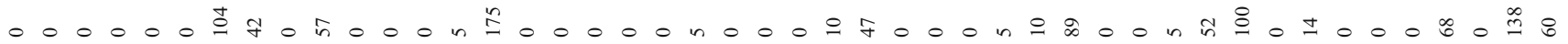
I \& \& \& \& \& \& \& \& \& \& \& \& \& \&

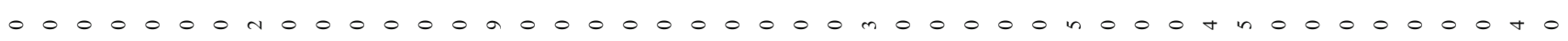

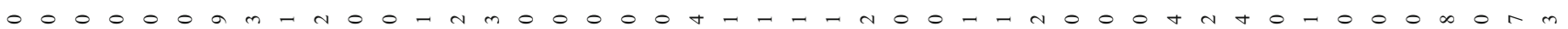

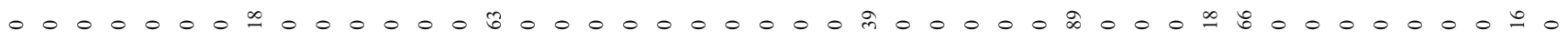

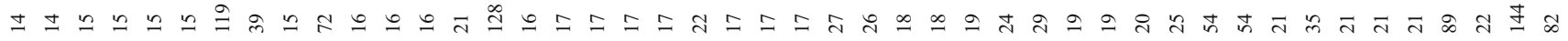
o o o o o o n h n

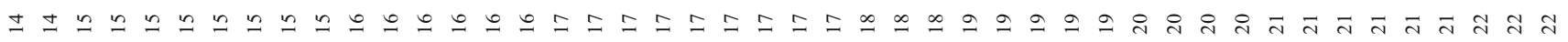

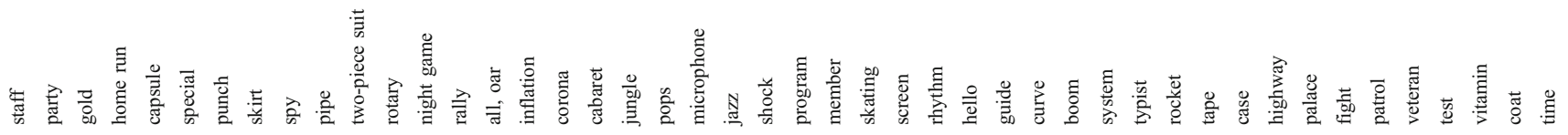

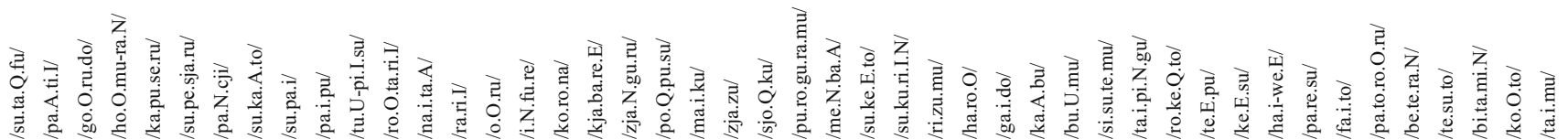

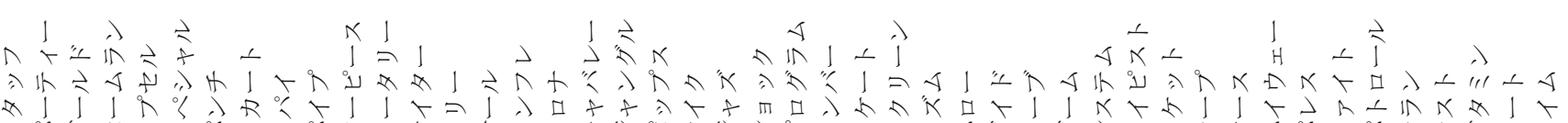

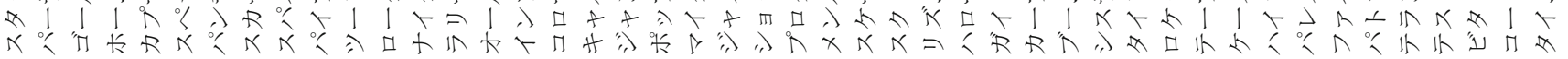

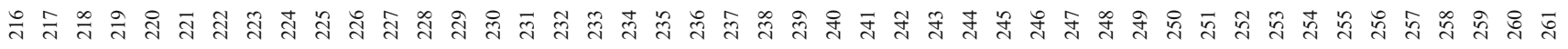




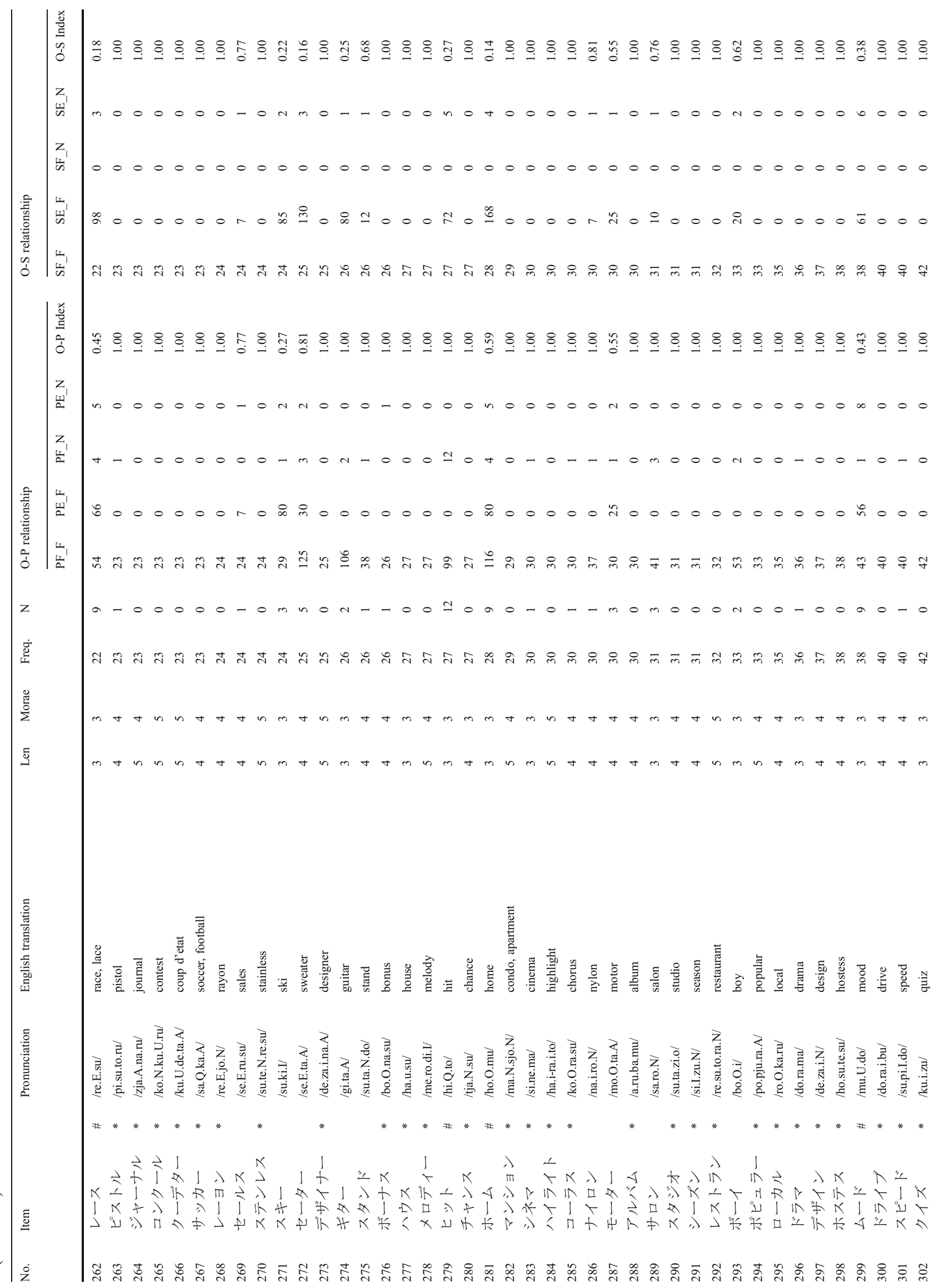




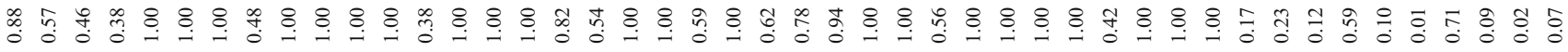

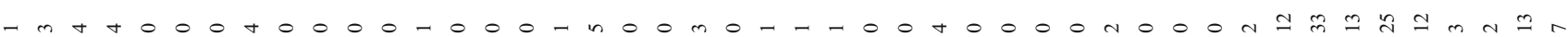

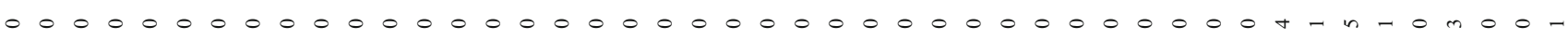

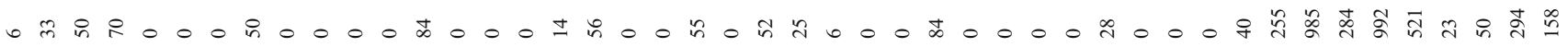

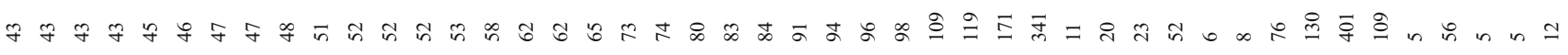
\& \& \& 웅 \& \& \& \& \& \& \& \& \& \&

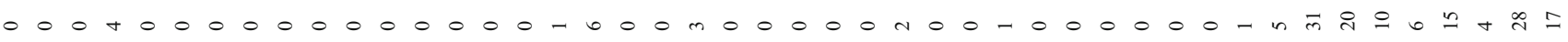

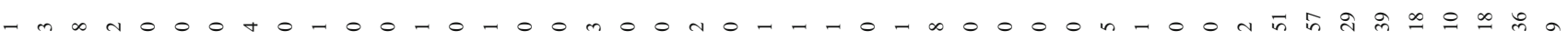

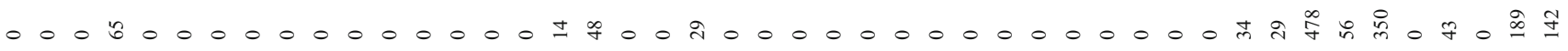

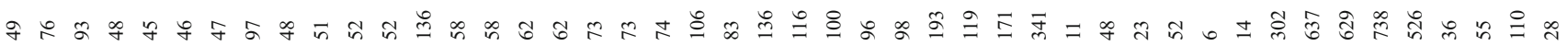

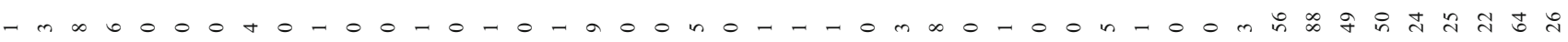

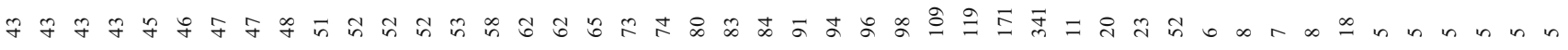

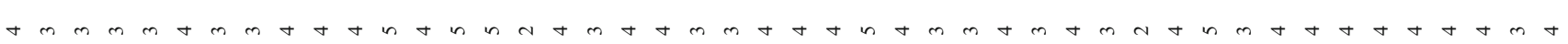

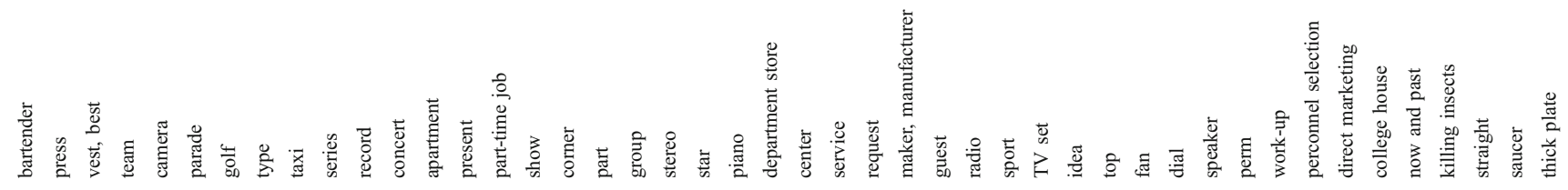

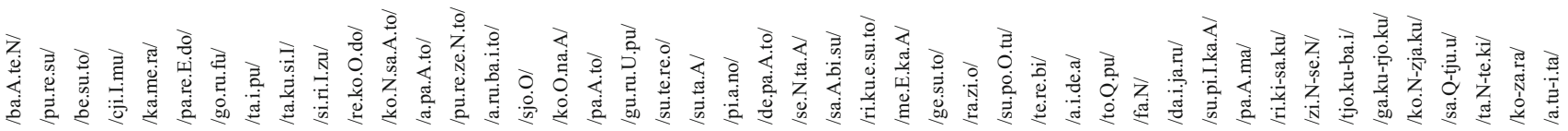

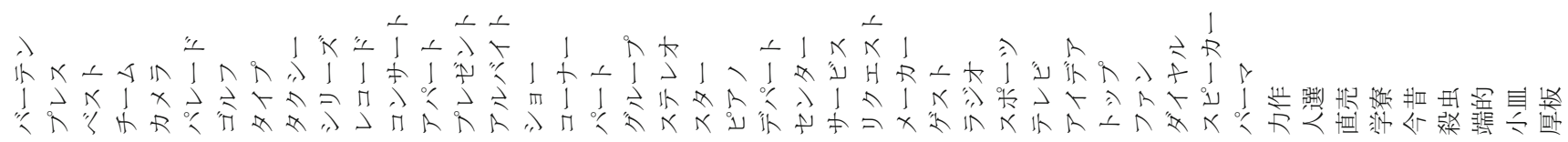

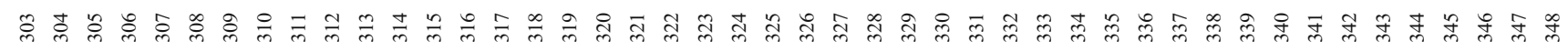




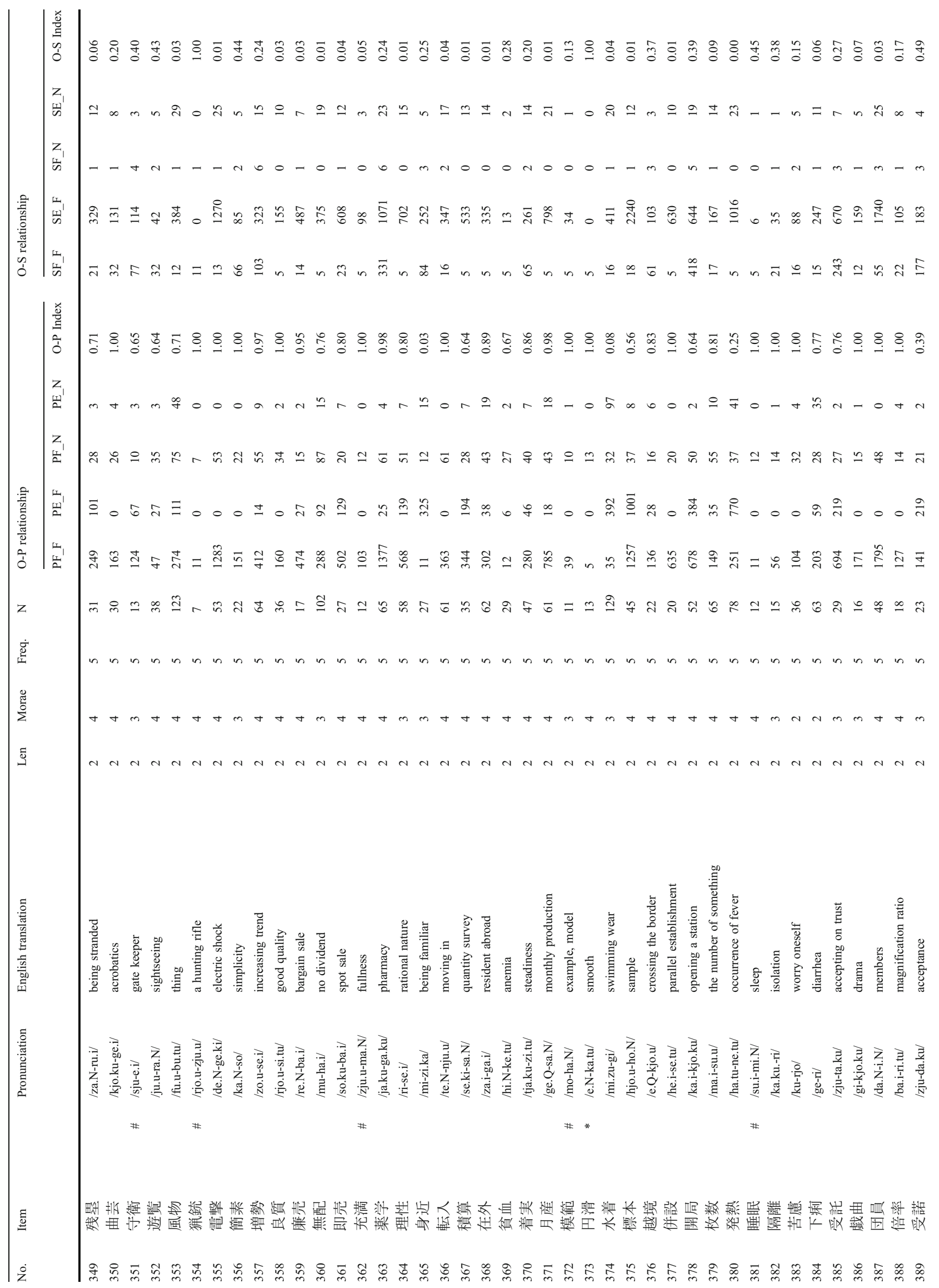




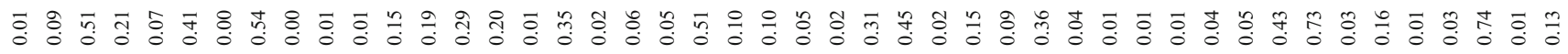

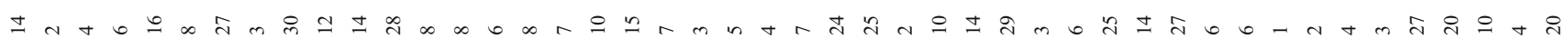

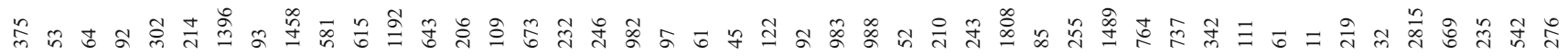

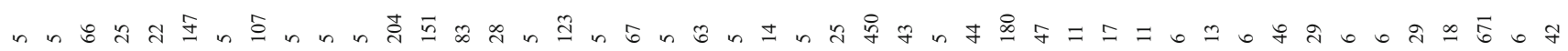

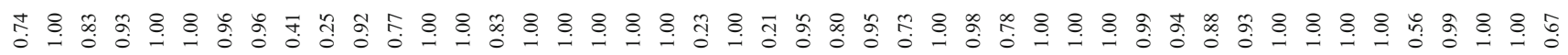

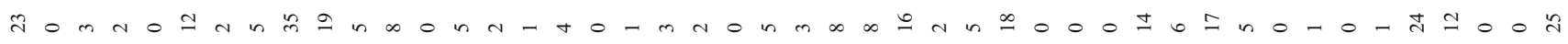

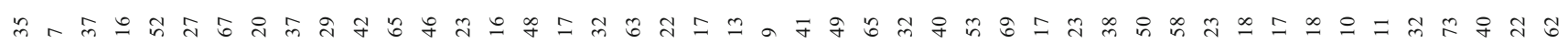

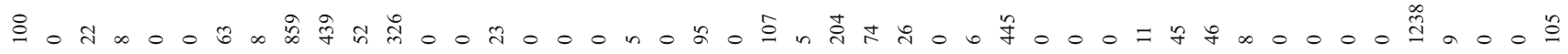

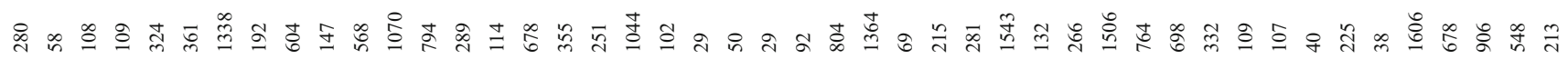

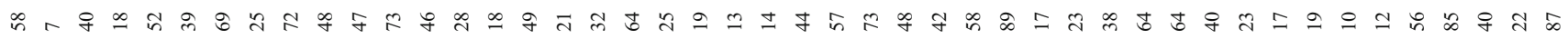

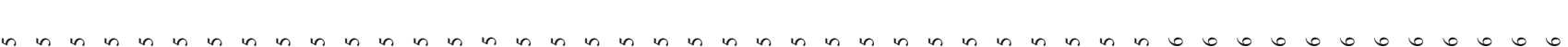

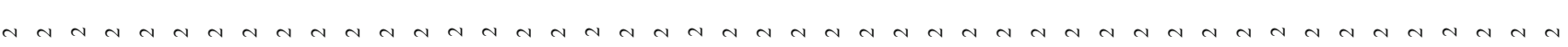

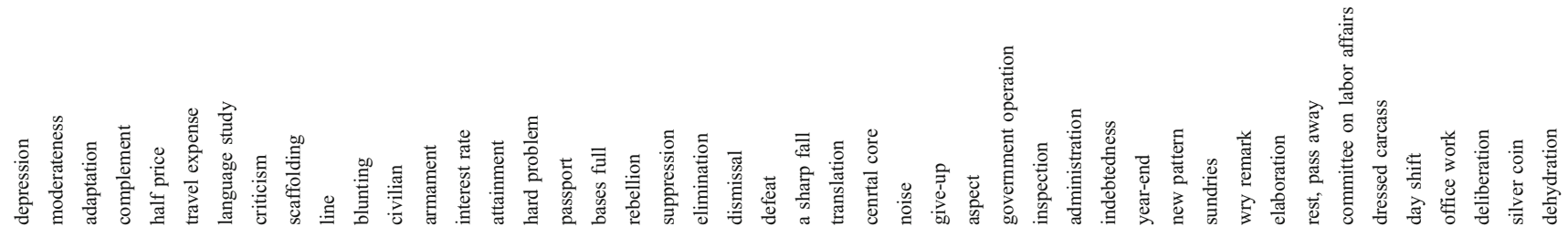

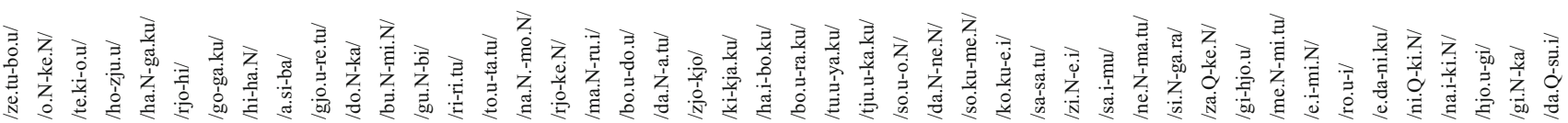

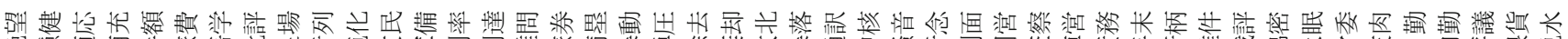

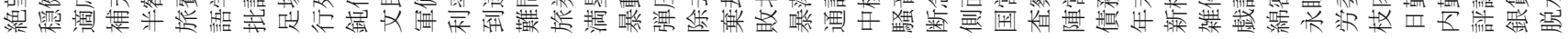

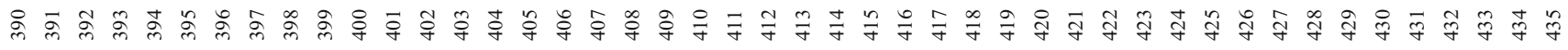




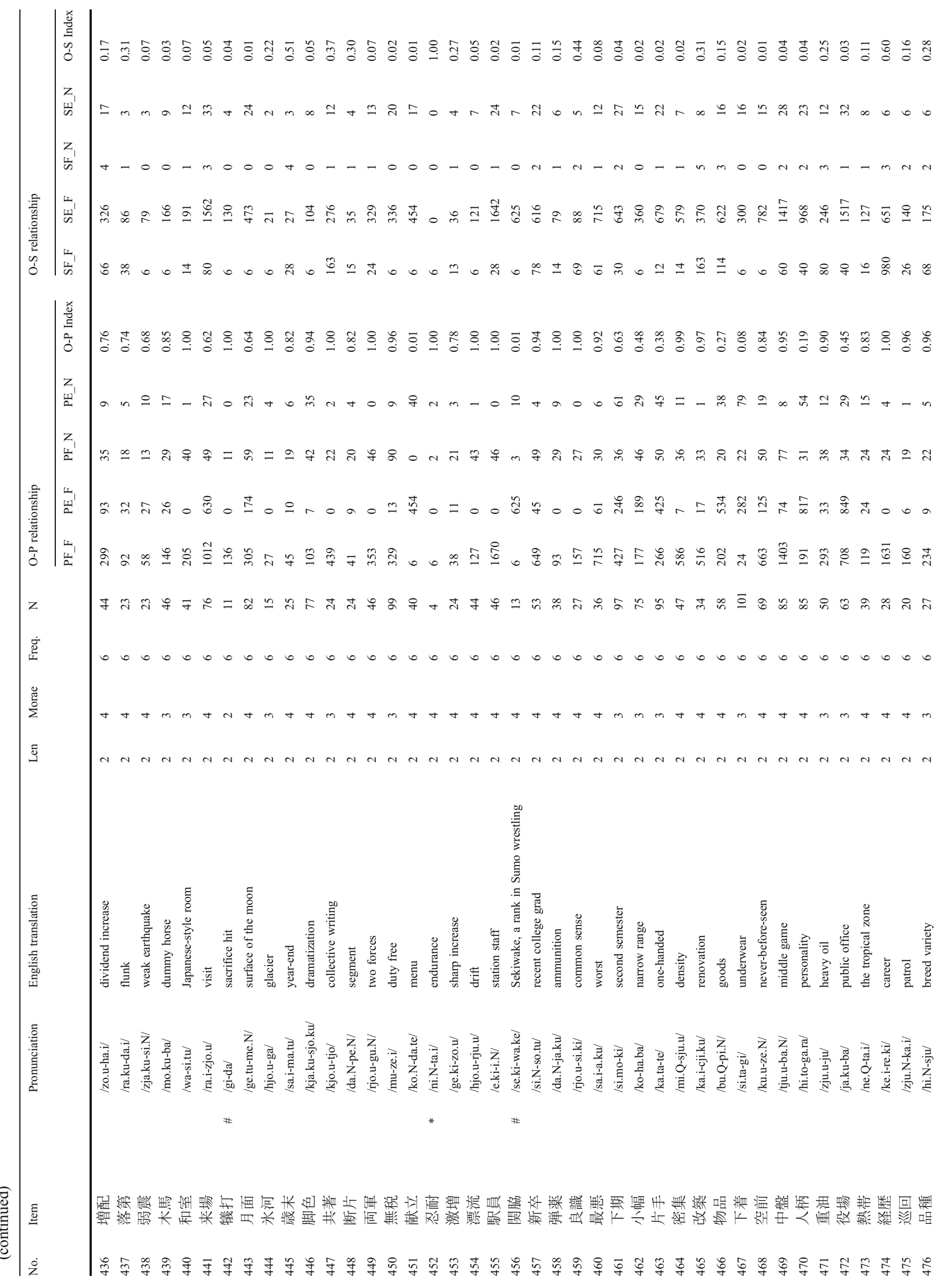




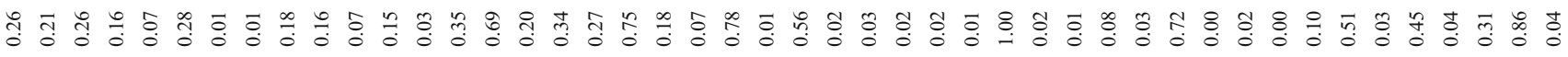
qna

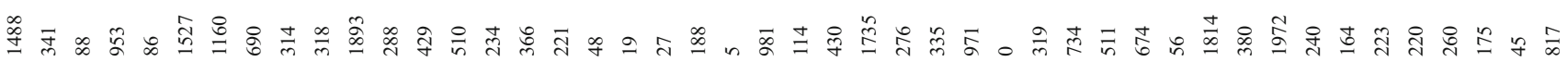

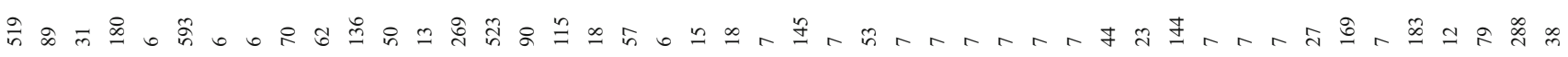

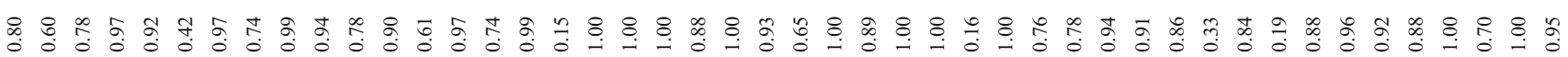

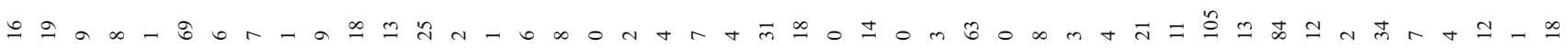

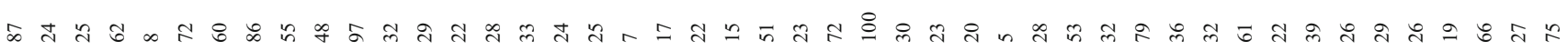

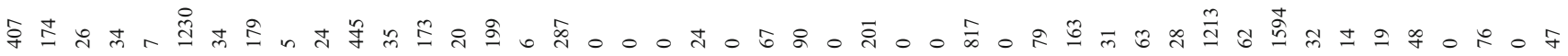

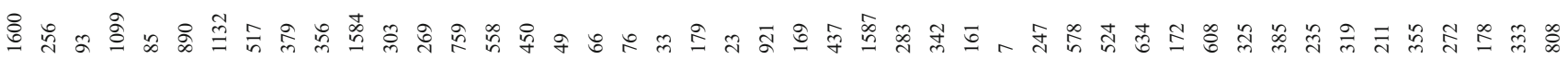

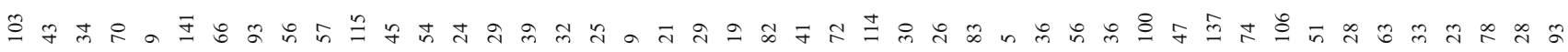

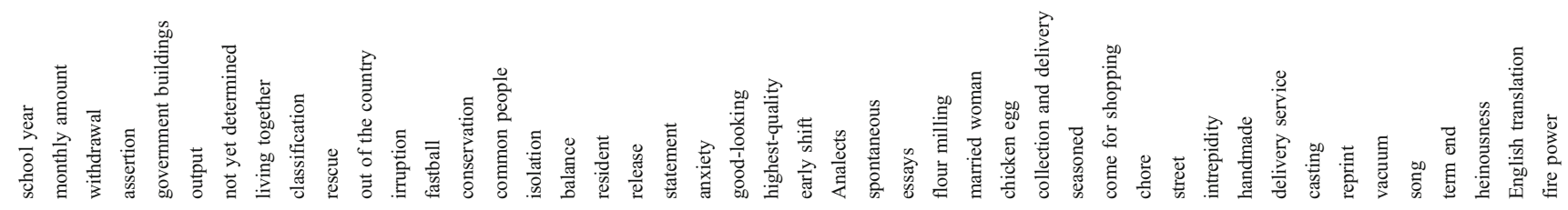

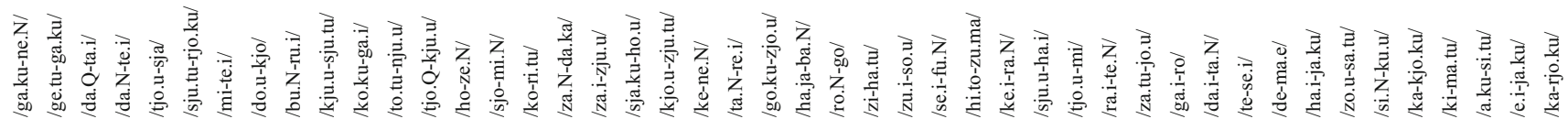

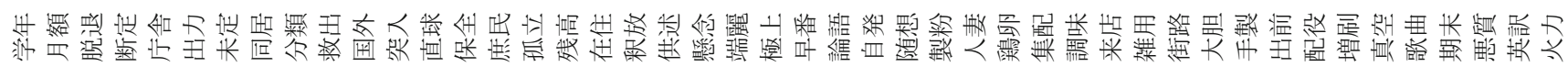

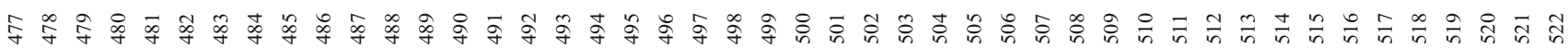




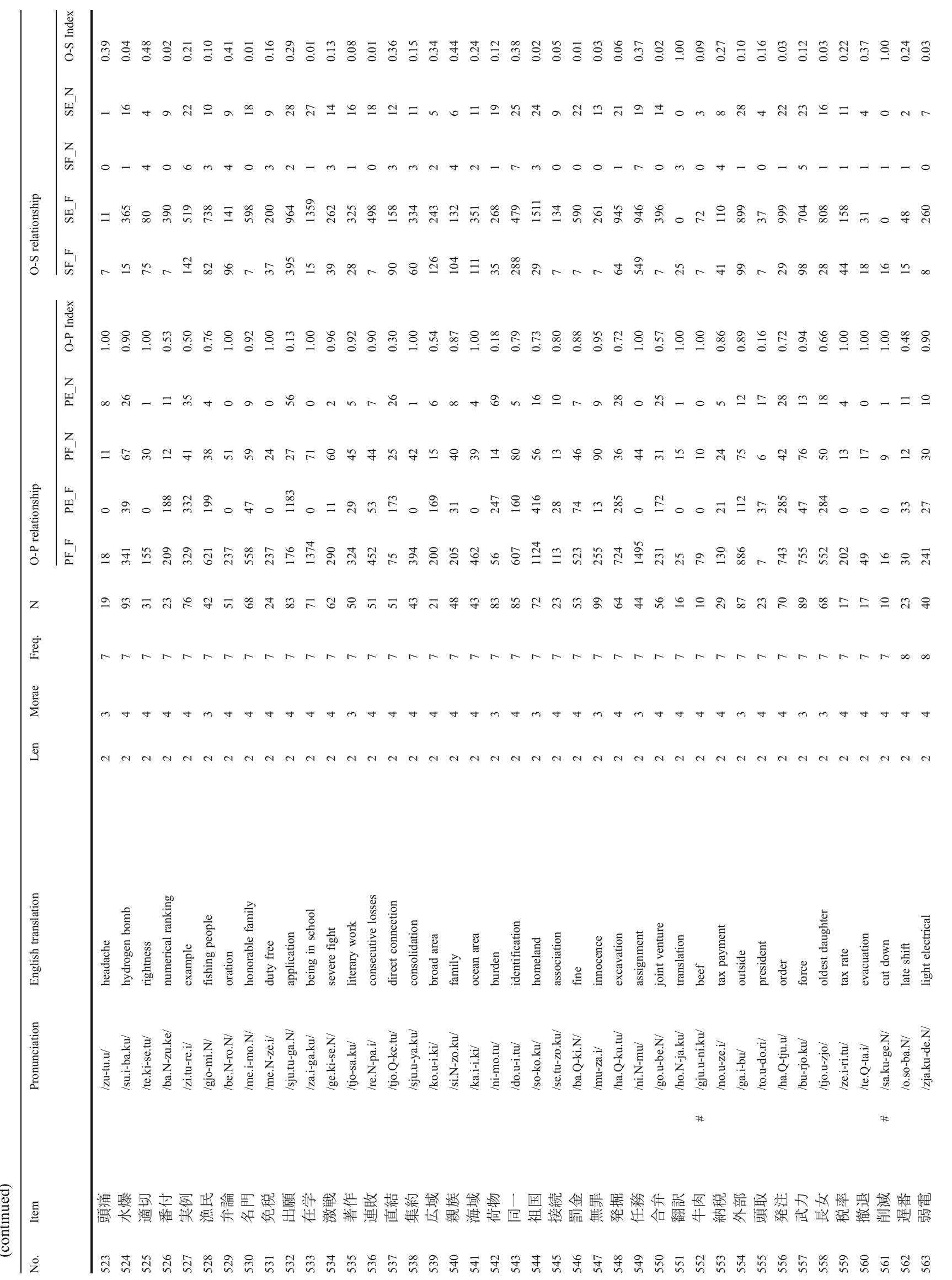




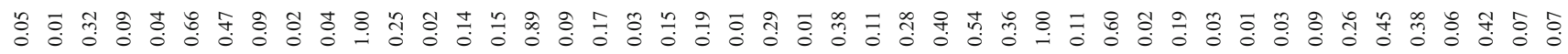

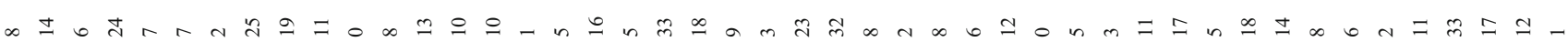

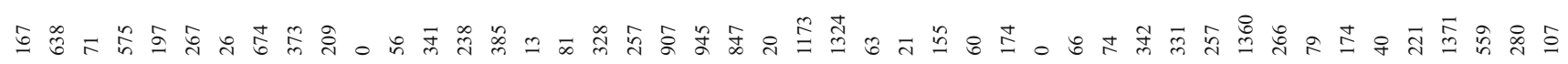

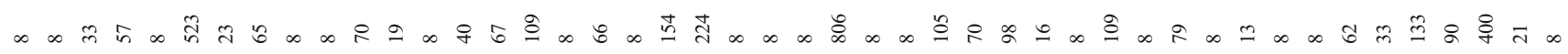

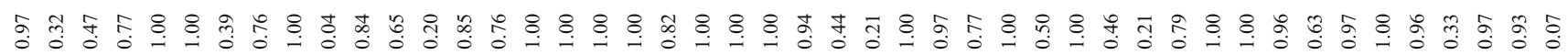

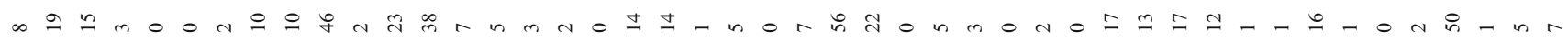

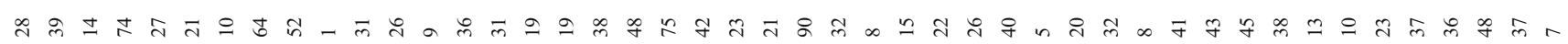

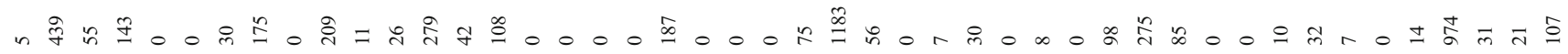

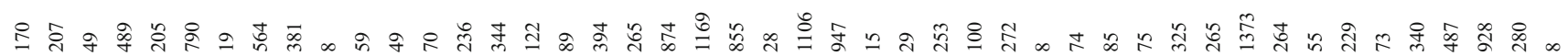

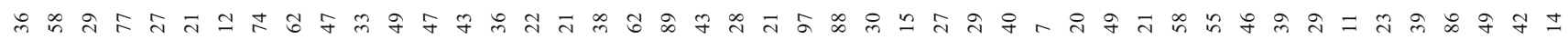

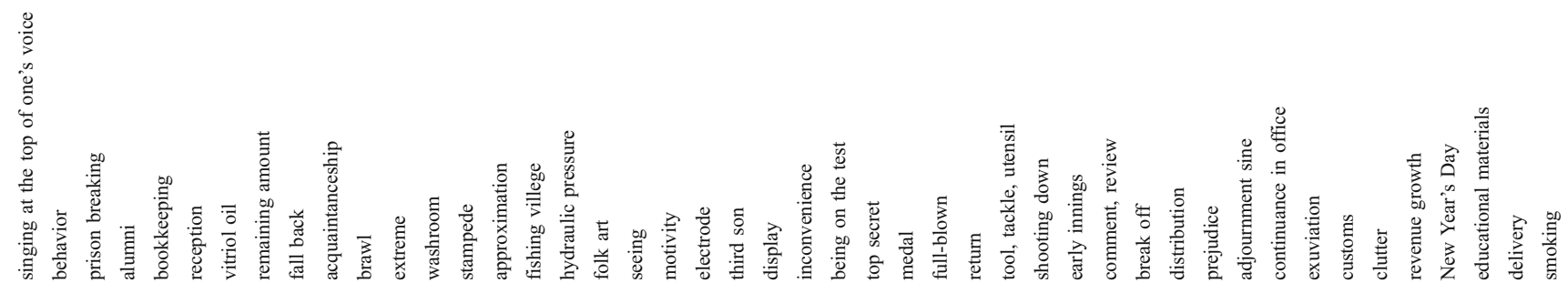

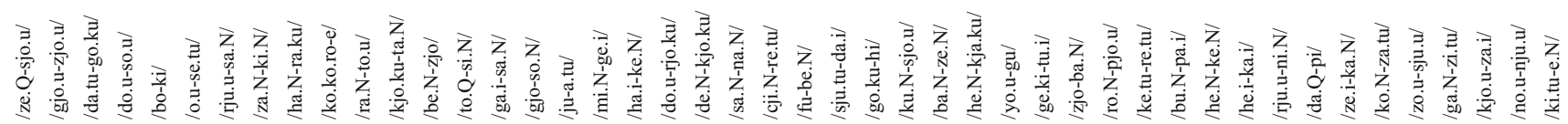

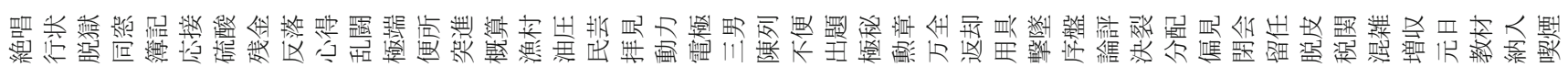

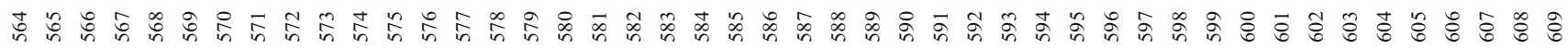




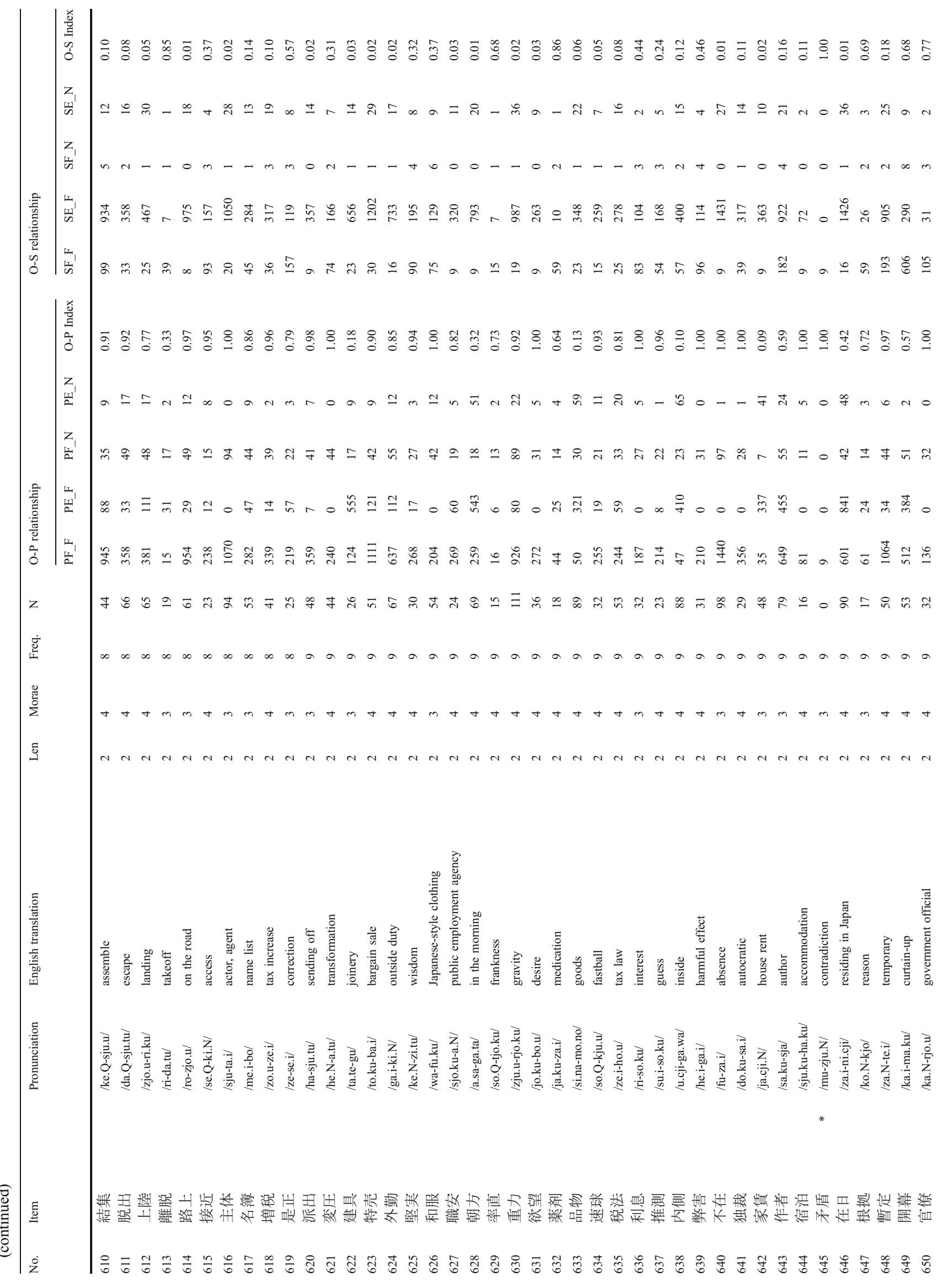




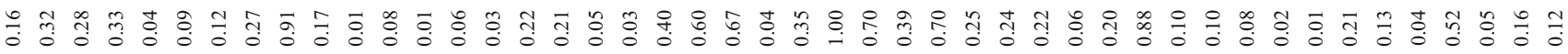

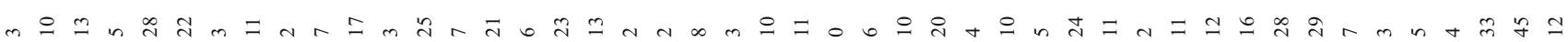

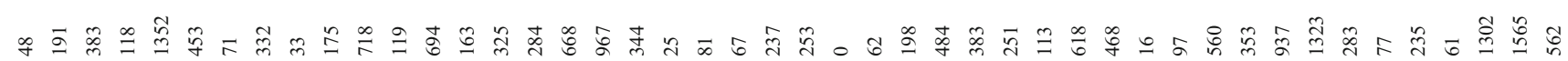

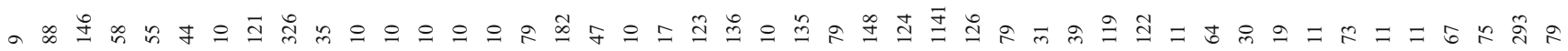
近 \& \&

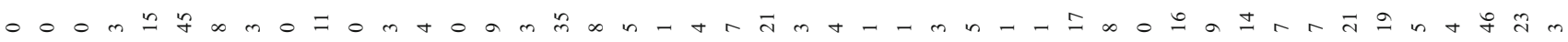

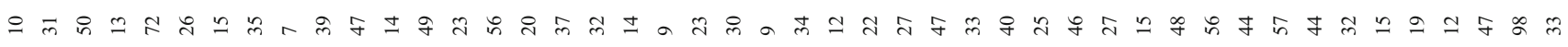
○。

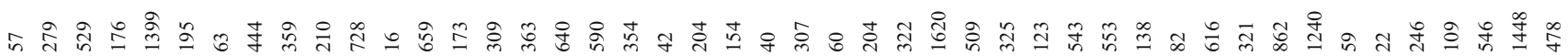

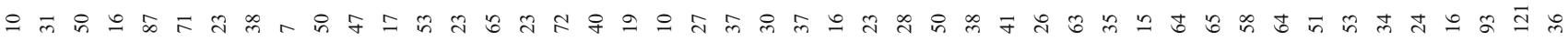

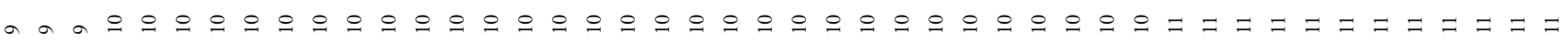

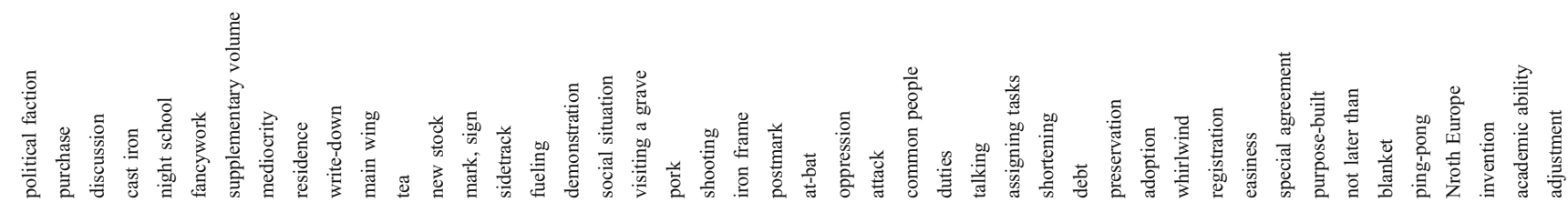

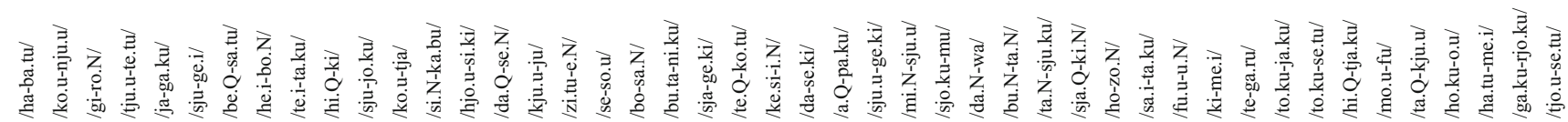
\#

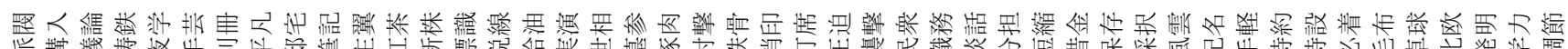
Бี 


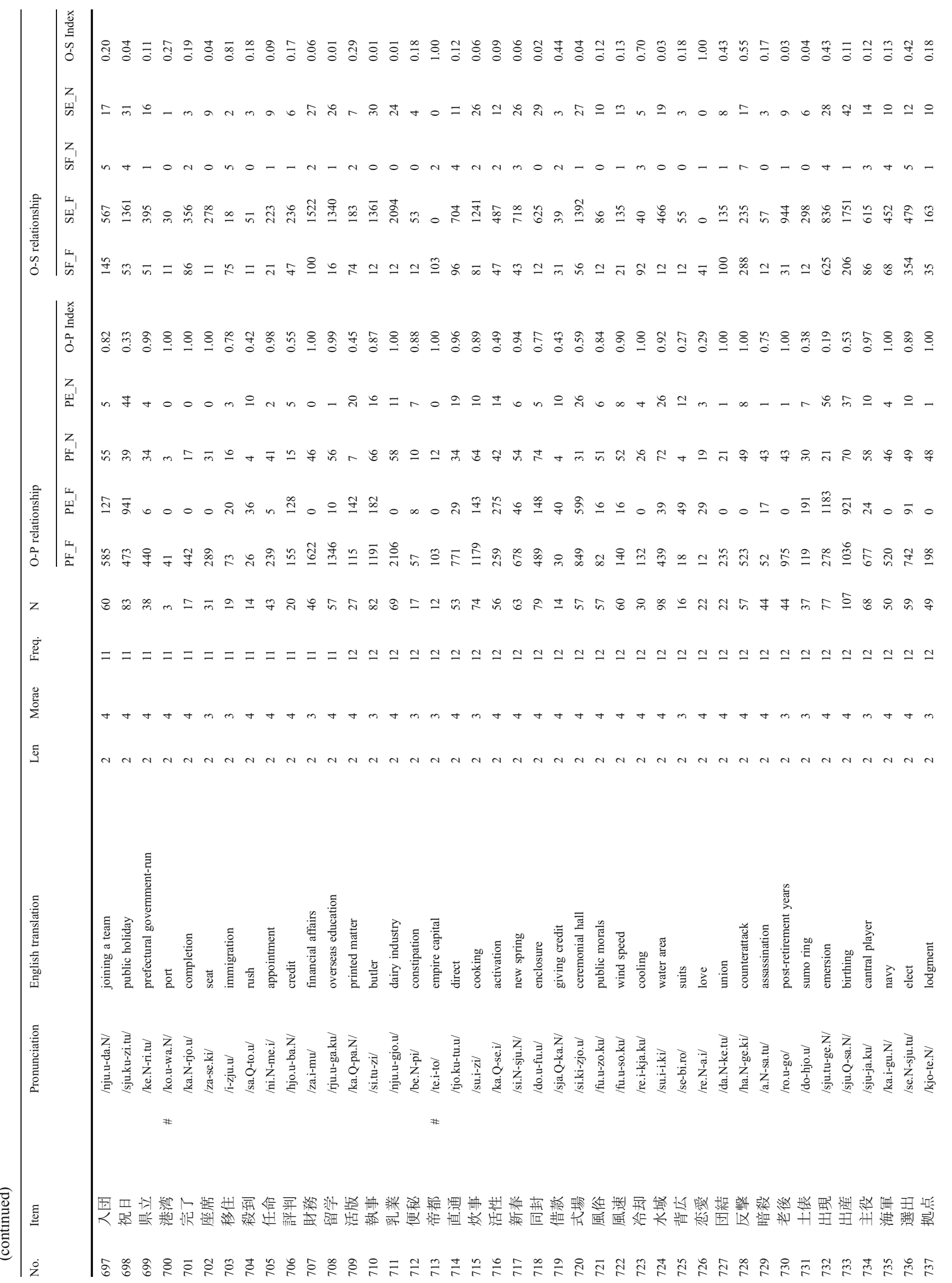




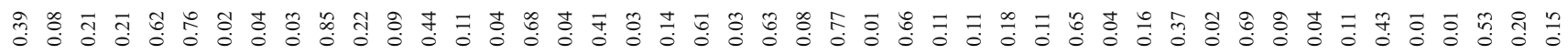

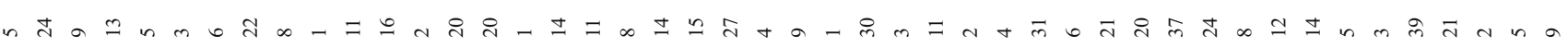

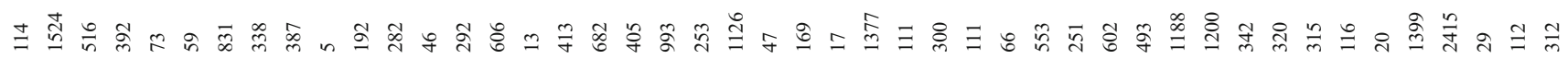

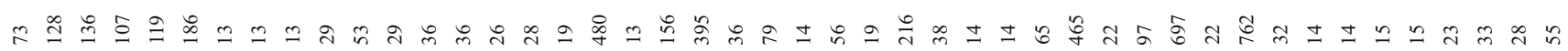

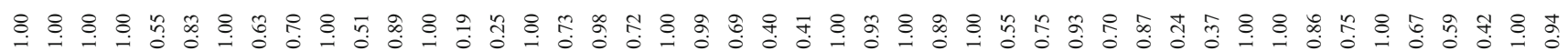

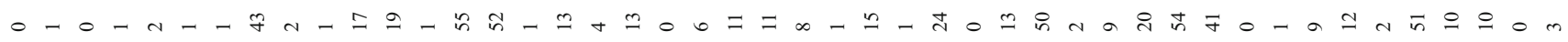

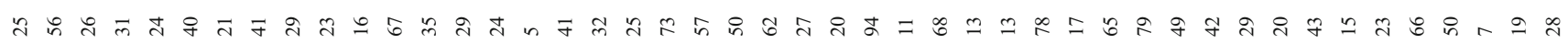

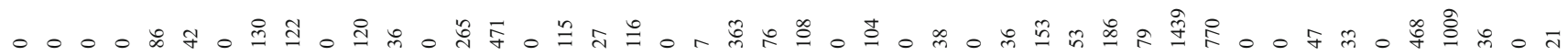

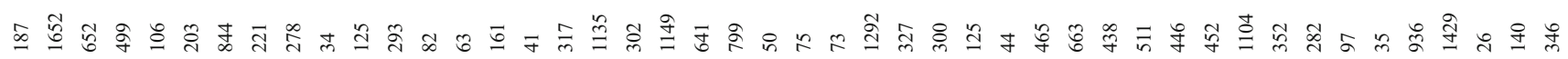

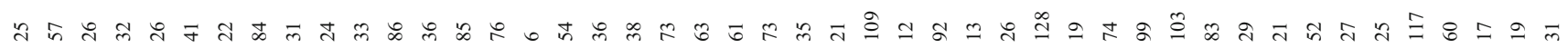

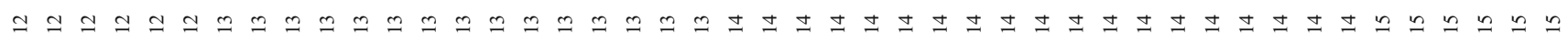

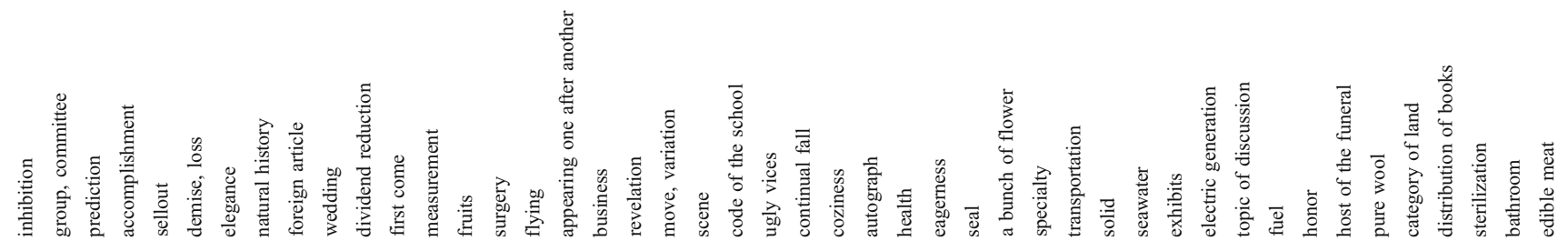

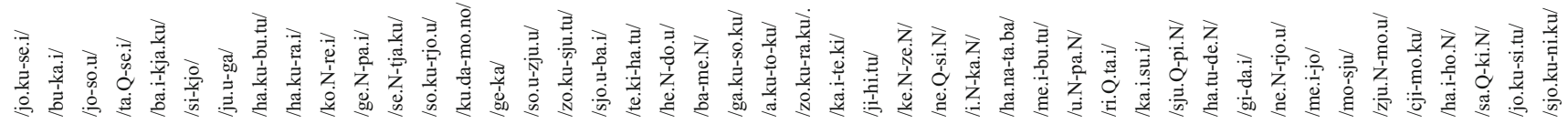

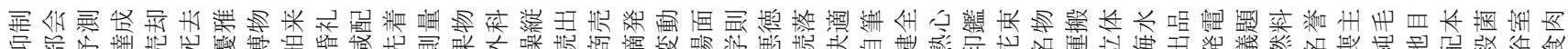

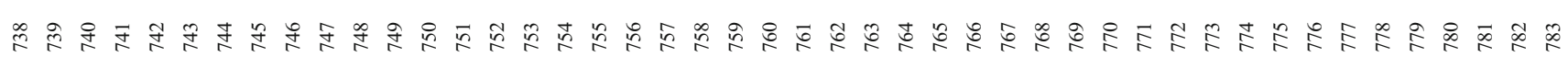




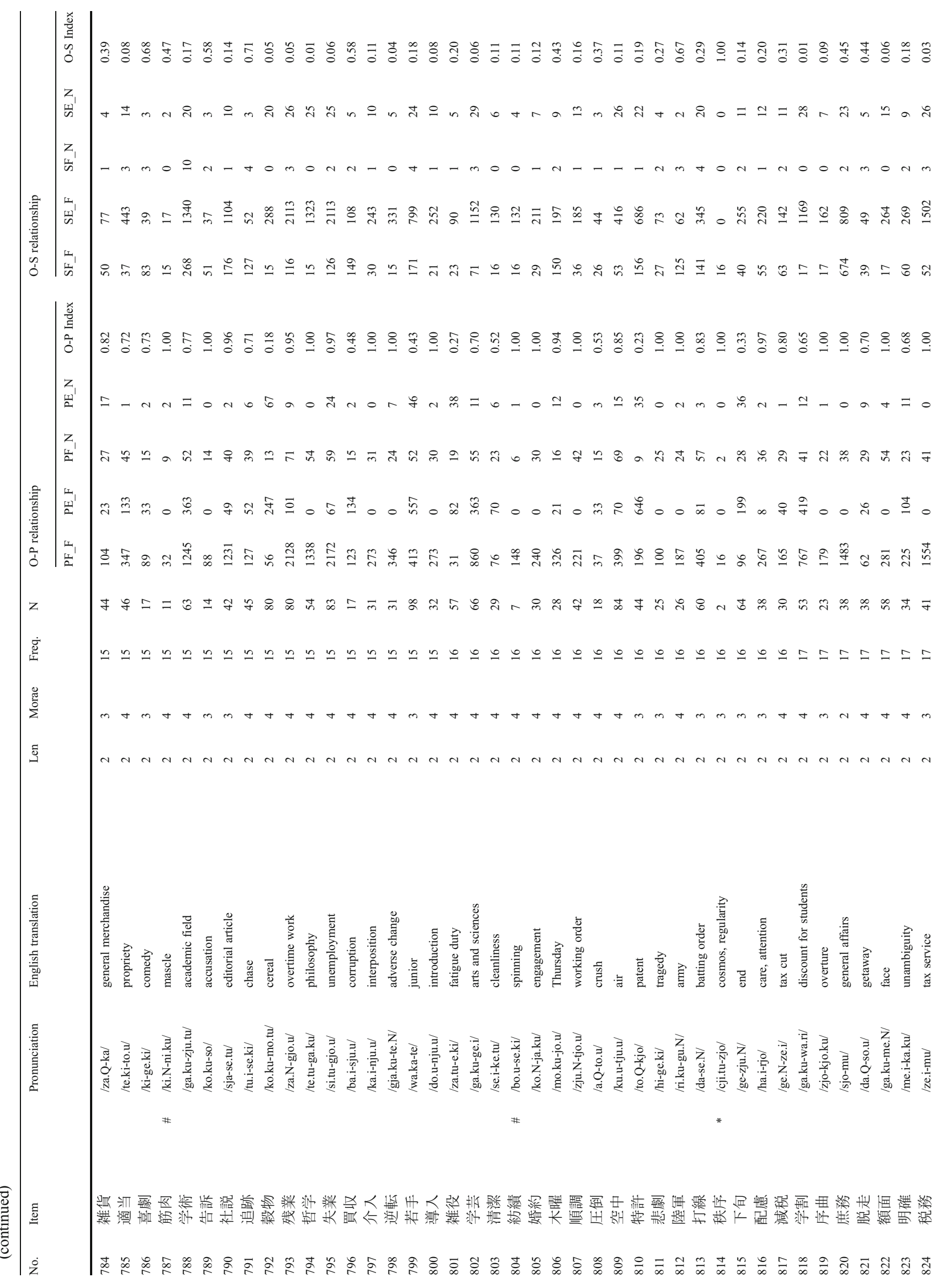




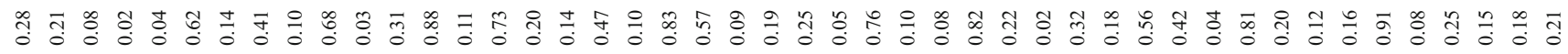

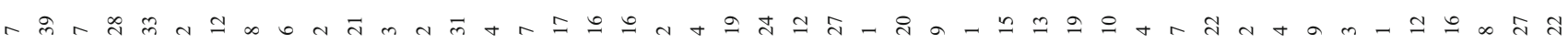

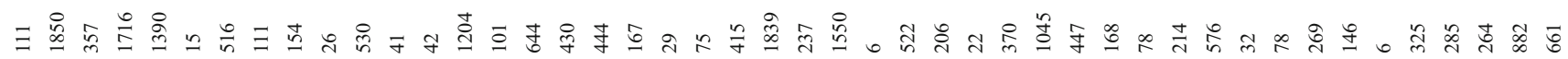

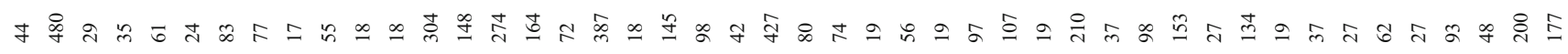

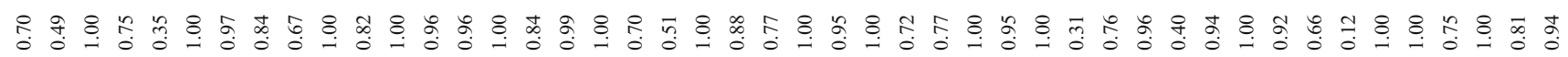

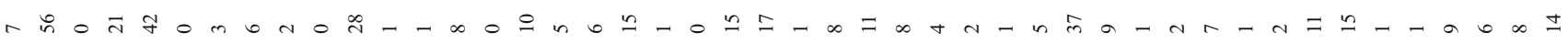
สำก

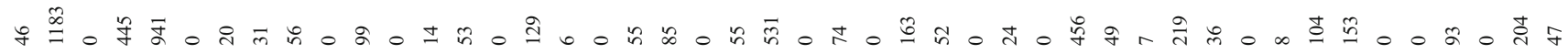

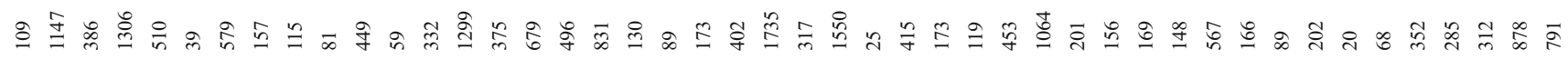

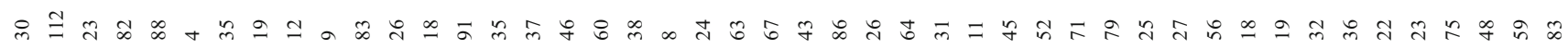

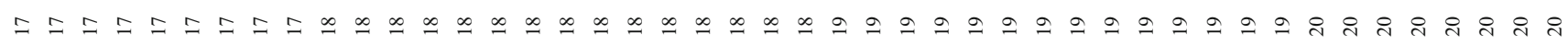

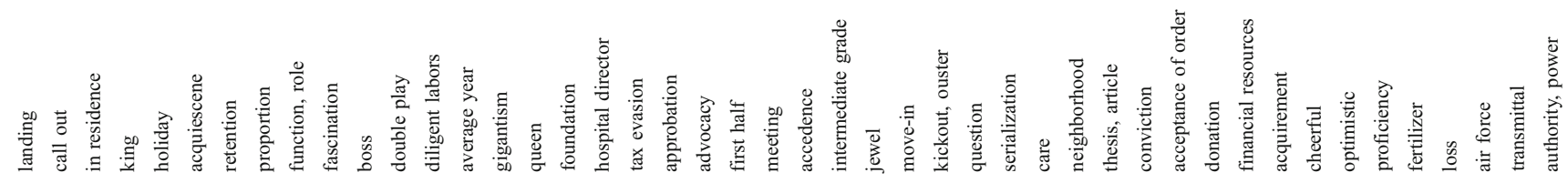

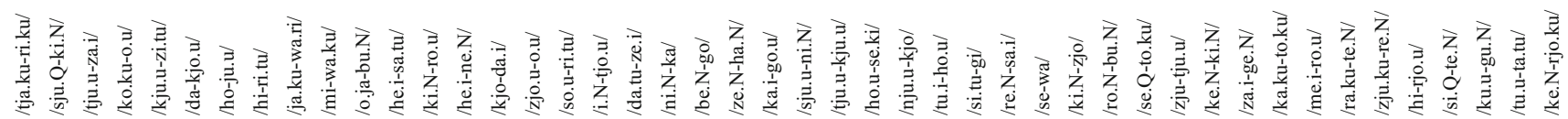
\# $\#$

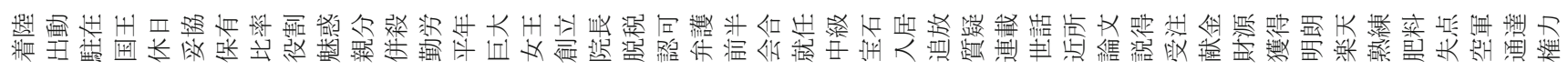

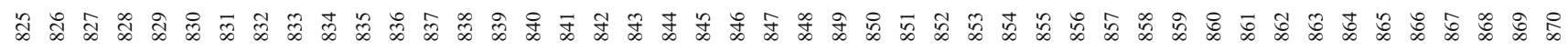




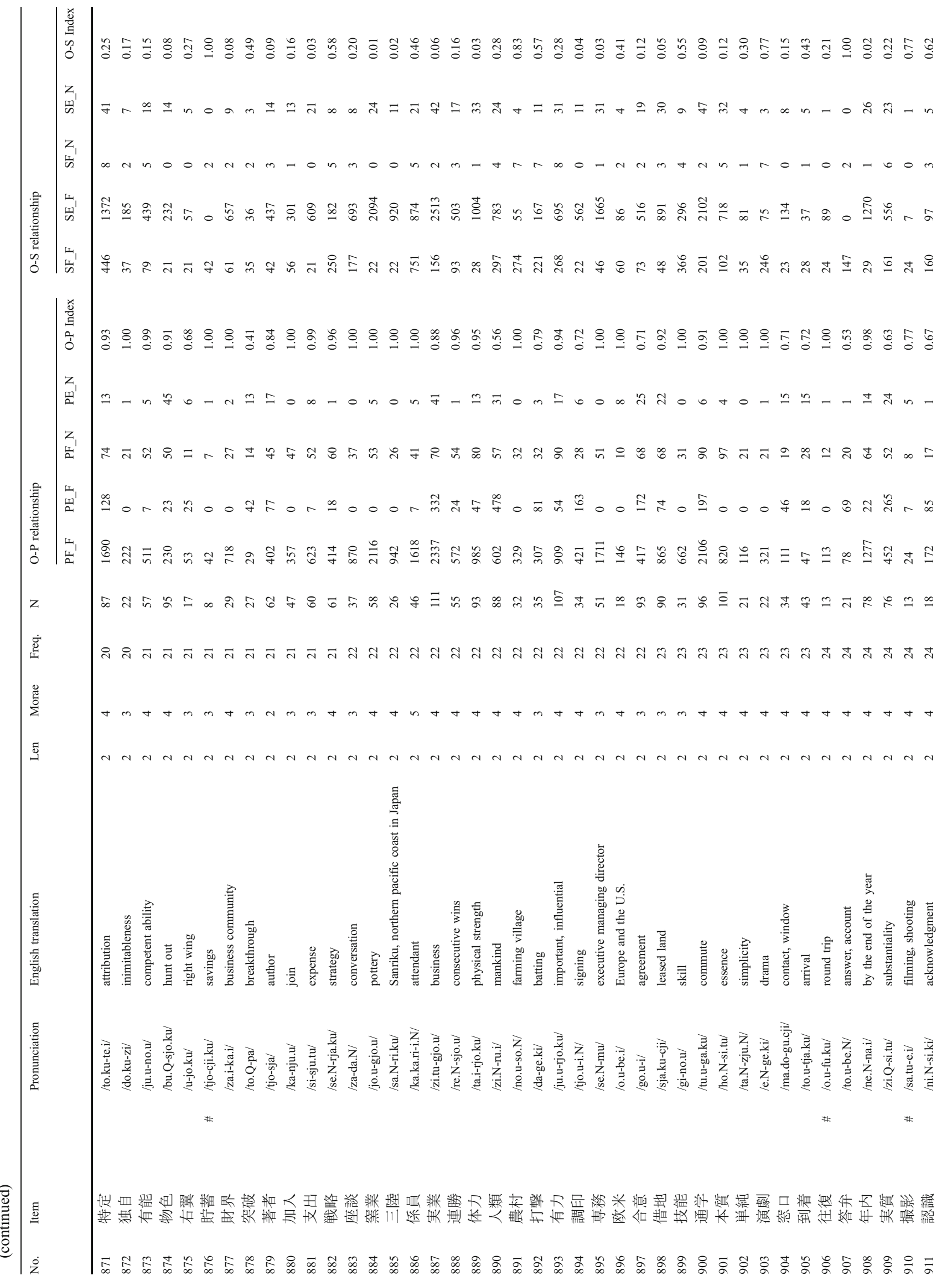




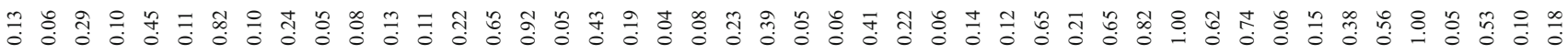

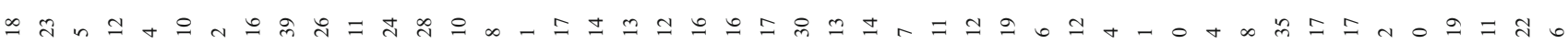

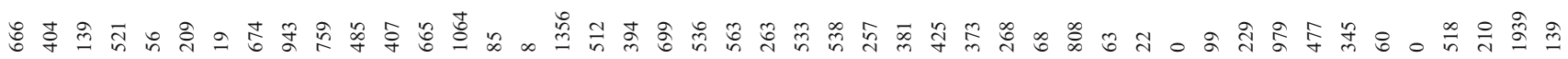

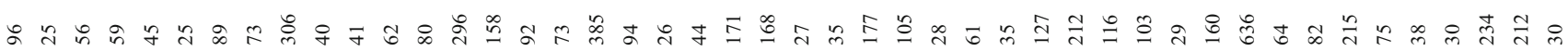

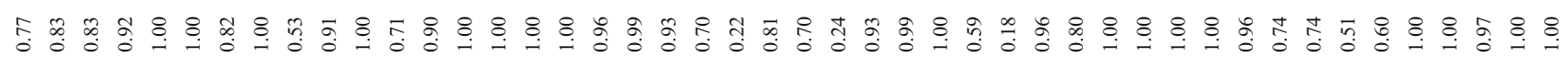
$a$ 政

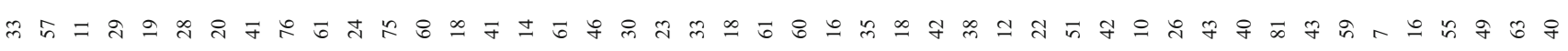

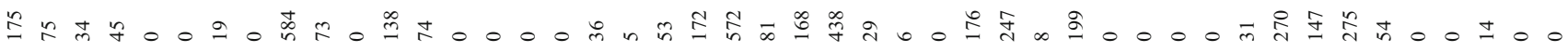

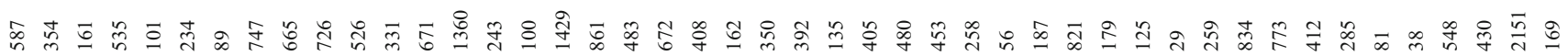

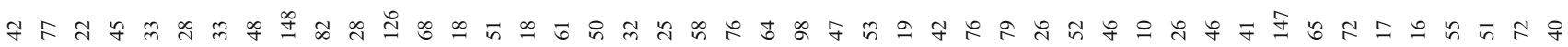

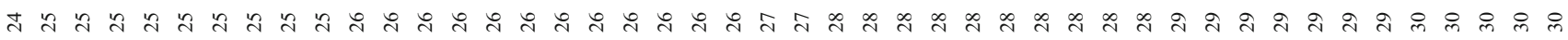

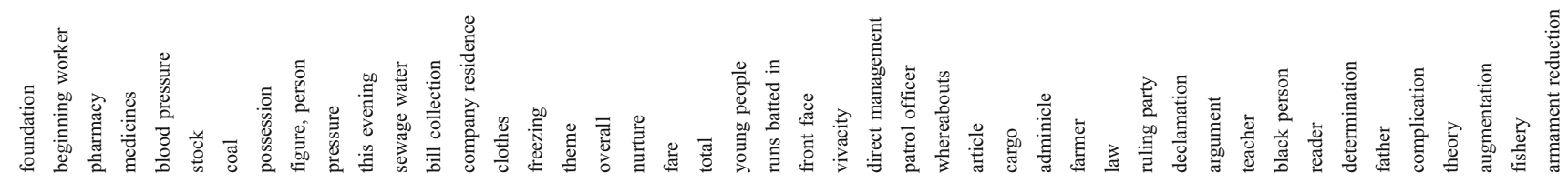

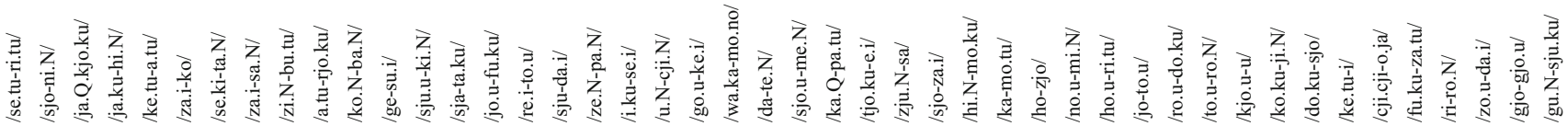

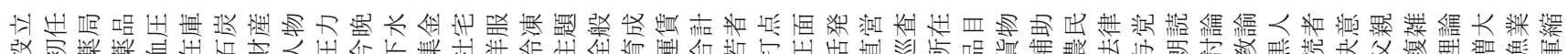

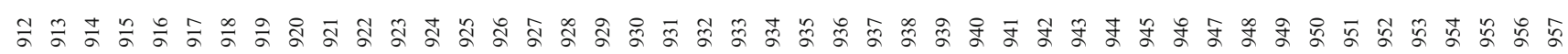




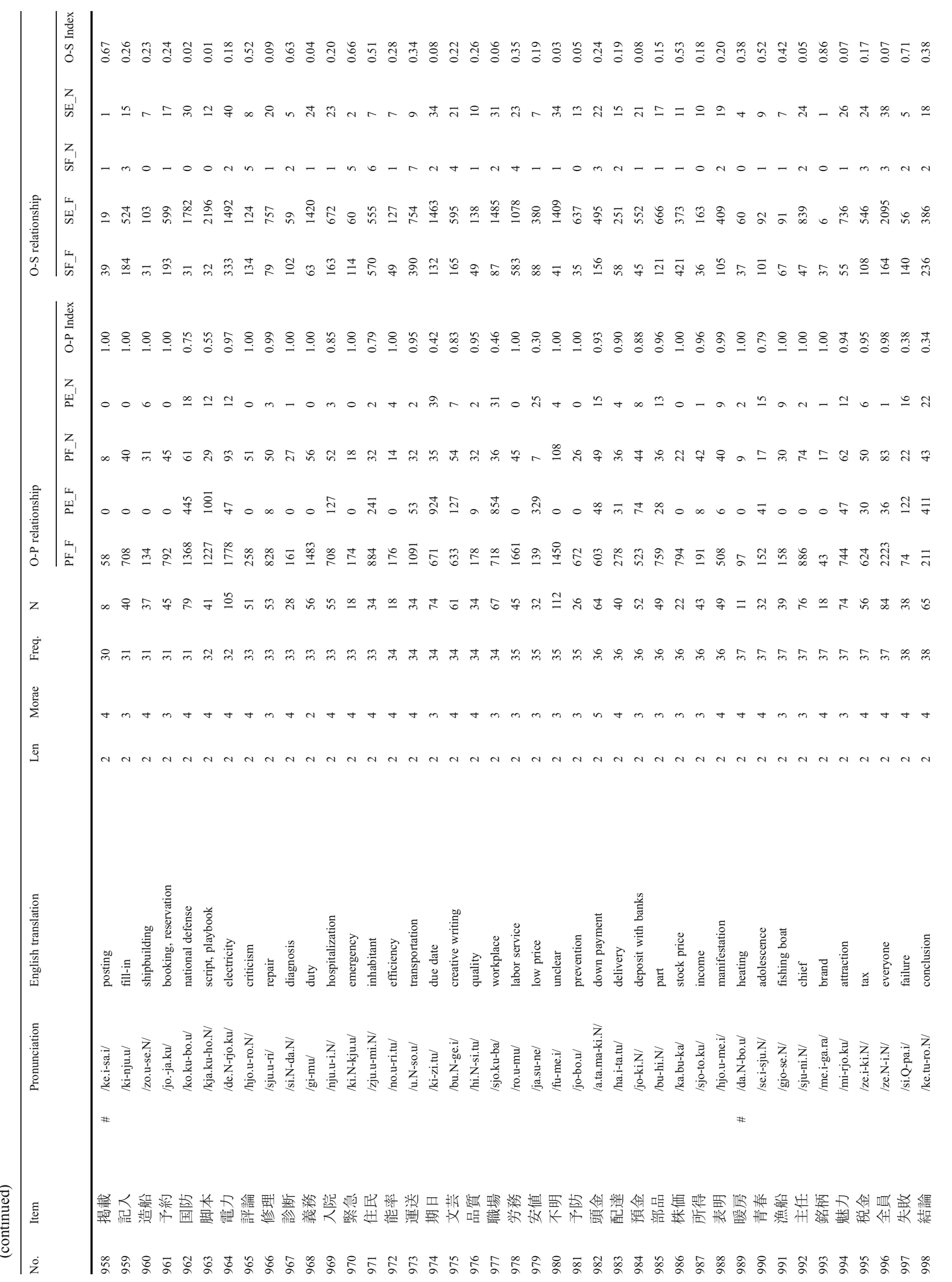




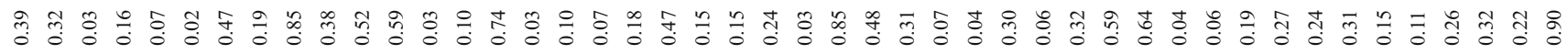
I

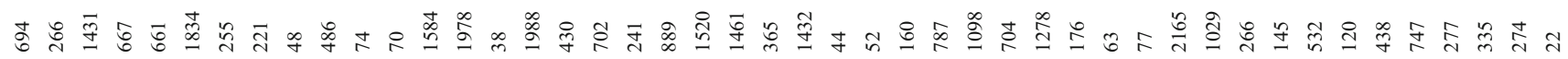

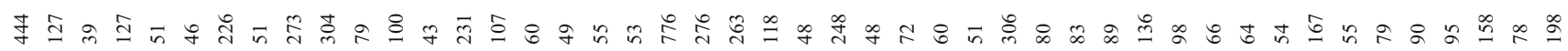

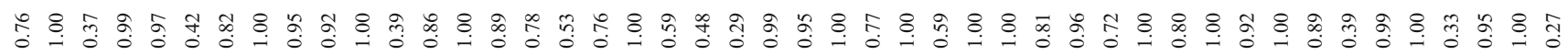

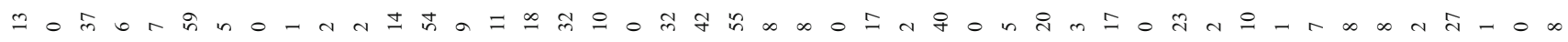

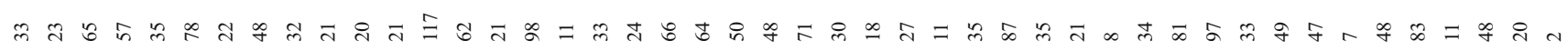

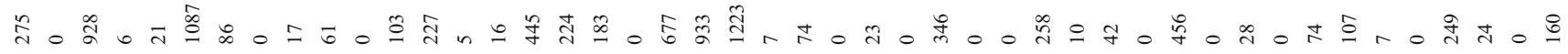

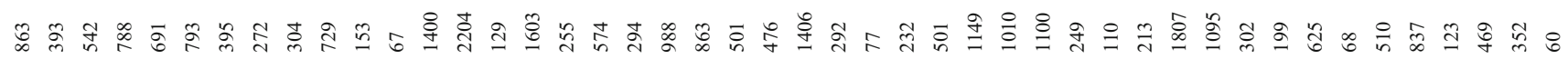

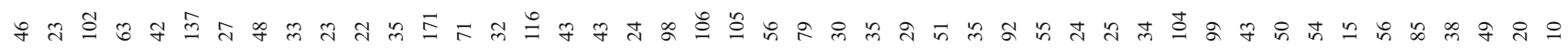

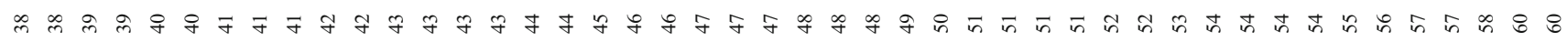

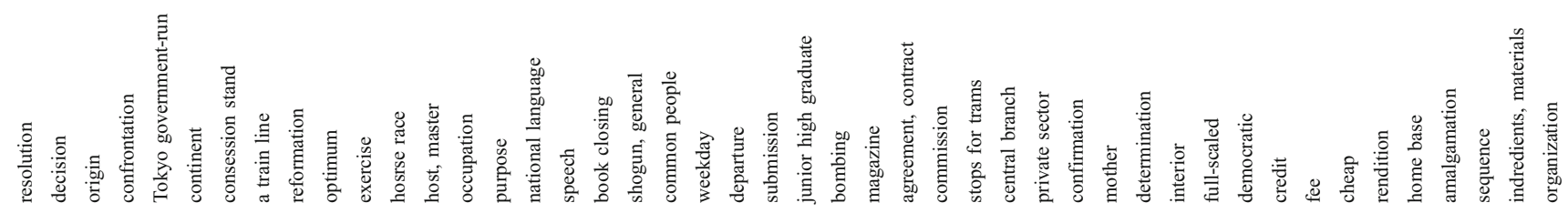

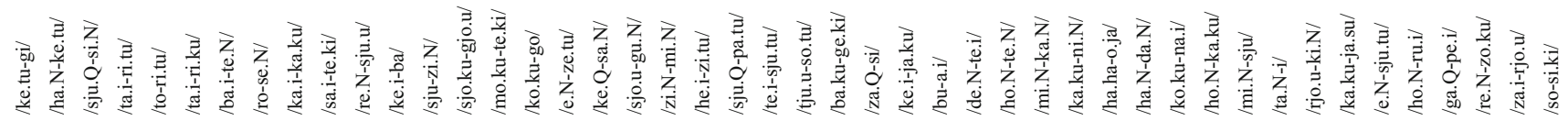

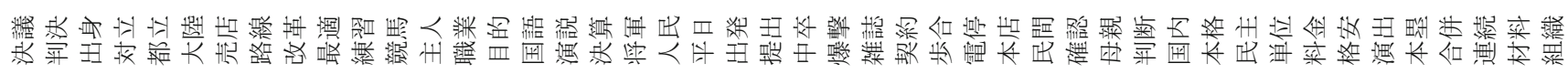

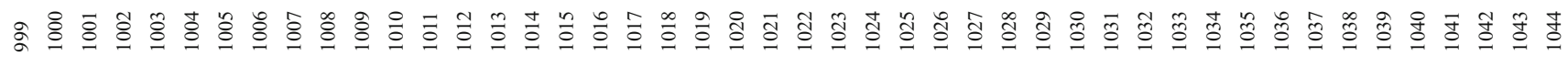




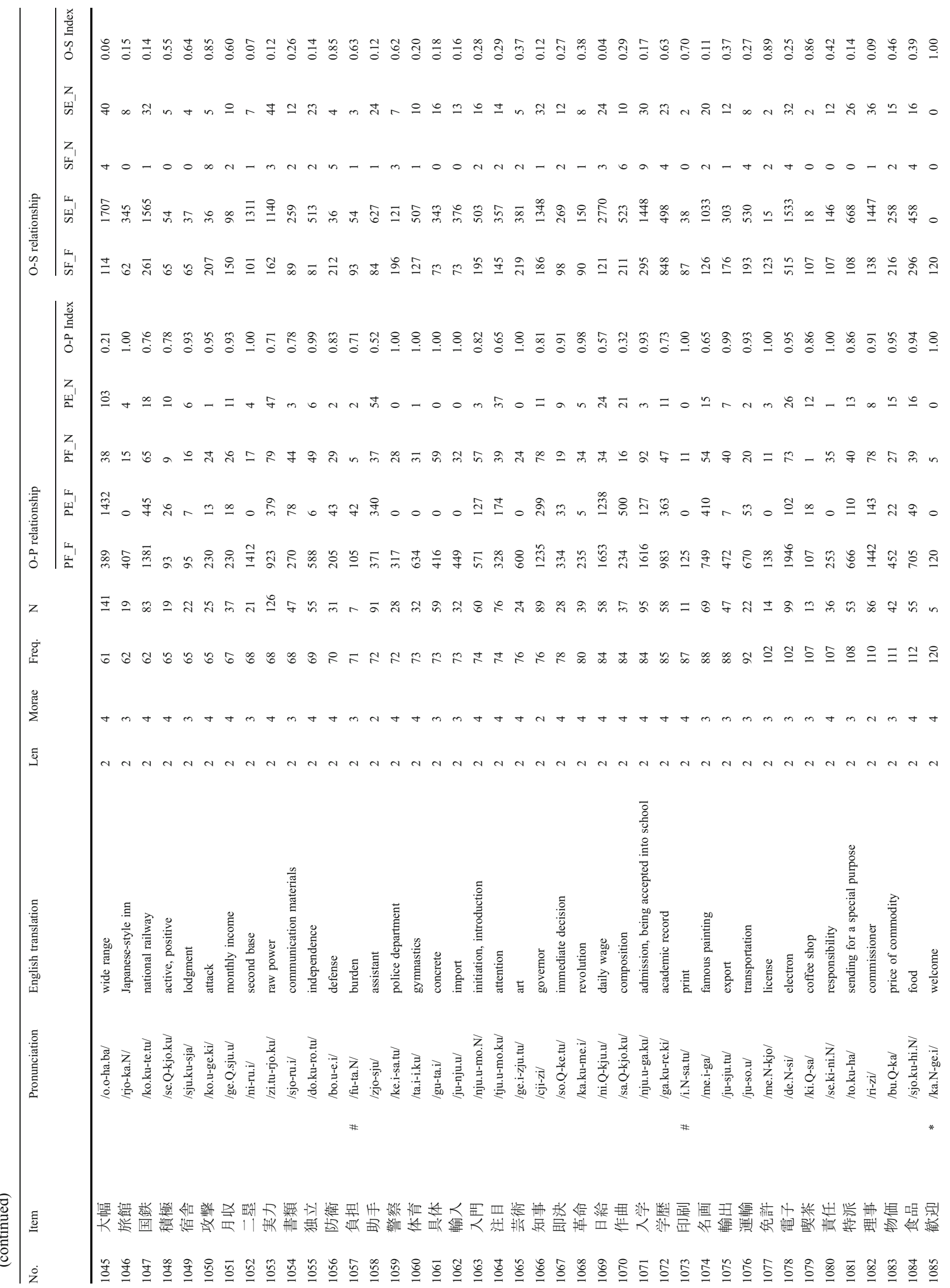




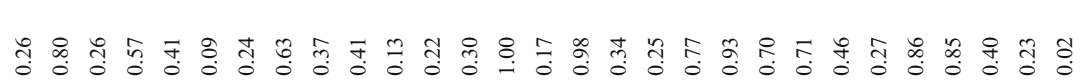

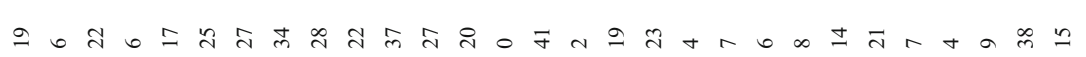

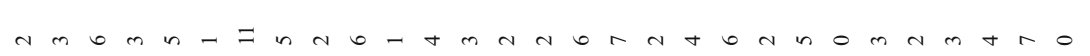

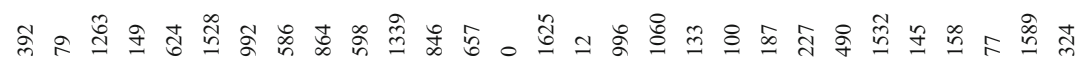

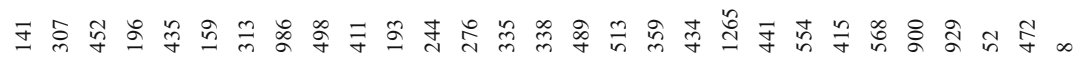

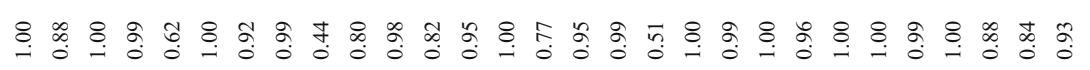

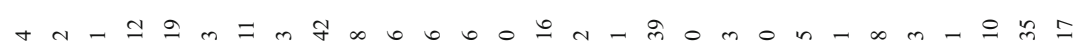

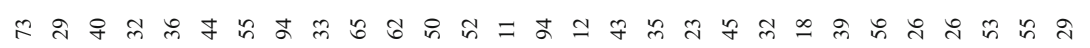

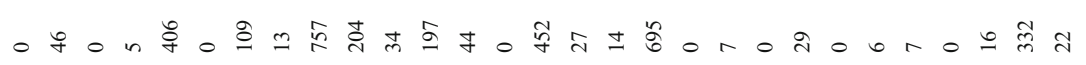

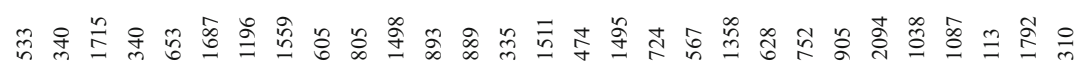

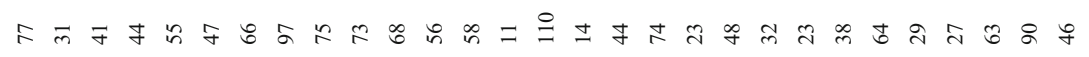

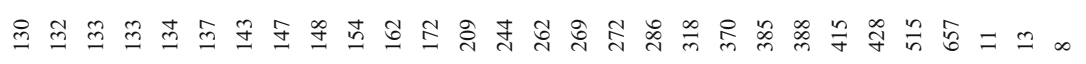

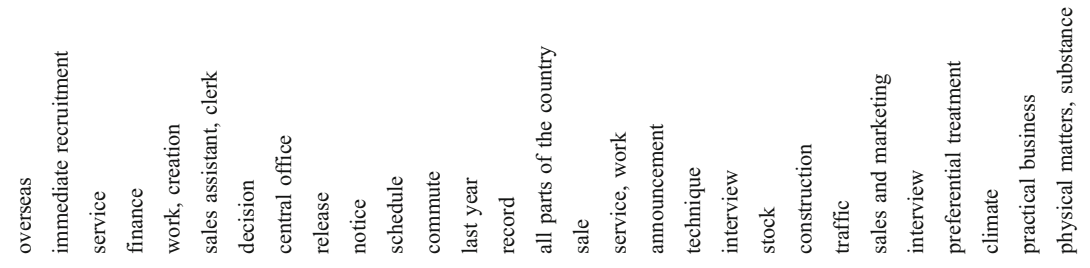

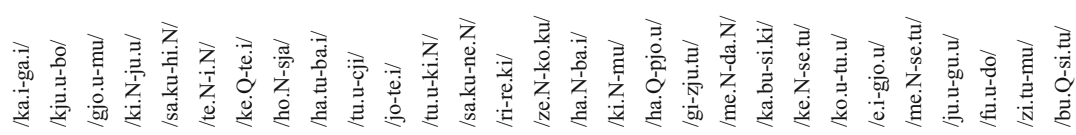

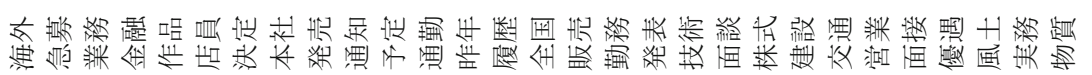

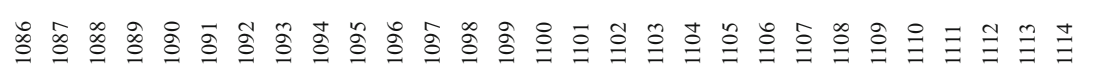




\section{References}

Amano, N., \& Kondo, K. (2003a). NTT detabesu shirizu: Nihongo no goi-tokusei dai 1-ki CD-ROM-ban [NTT database series: lexical properties of Japanese, Vol. 1, CD-ROM Version]. Tokyo: Sanseido (in Japanese).

Amano, N., \& Kondo, K. (2003b). NTT detabesu shirizu: Nihongo no goi-tokusei dai 2-ki CD-ROM-ban [NTT database series: lexical properties of Japanese, Vol. 2, CD-ROM Version]. Tokyo: Sanseido (in Japanese).

Besner, D., \& Hildebrandt, N. (1987). Orthographic and phonological codes in the oral reading of Japanese Kana. Journal of Experimental Psychology. Learning, Memory, and Cognition, 13, 335-343. doi:10.1037/0278-7393.13.2.335

Coltheart, M. (1978). Lexical access in simple reading tasks. In G. Underwood (Ed.), Strategies of information processing (pp. 151216). London: Academic Press.

Coltheart, M. (2005). Modeling reading: The dual-route approach. In M. J. Snowling \& C. Hulmes (Eds.), The science of reading: A handbook (pp. 6-23). Malden: Blackwell.

Coltheart, M., Curtis, B., Atkins, P., \& Haller, M. (1993). Models of reading aloud: Dual-route and parallel-distributed-processing approaches. Psychological Review, 100, 589-608.

Coltheart, M., Davelaar, E., Jonasson, J. T., \& Besner, D. (1977). Access to the internal lexicon. In S. Dornic (Ed.), Attention and performance VI (pp. 535-555). Hillsdale: Erlbaum.

Coltheart, M., Rastle, K., Perry, C., Langdon, R., \& Ziegler, J. (2001). DRC: A dual-route cascaded model of visual word recognition and reading aloud. Psychological Review, 108, 204-256.

Feldman, L. B., \& Turvey, M. T. (1980). Words written in Kana are named faster than the same words written in Kanji. Language and Speech, 23, 141-147.

Forster, K. I., Davis, C., Schoknecht, C., \& Carter, R. (1987). Masked priming with graphemically related forms: Repetition or partial activation? The Quarterly Journal of Experimental Psychology, 39 A, 211-251.

Frost, R. (2005). Orthographic systems and skilled word recognition processes in reading. In M. J. Snowling \& C. Hulmes (Eds.), The science of reading: A handbook (pp. 272-295). Malden: Blackwell.

Frost, R., Katz, L., \& Bentin, S. (1987). Strategies for visual word recognition and orthographical depth: A multilingual comparison. Journal of Experimental Psychology. Human Perception and Performance, 13, 104-115.

Fushimi, T., Ijuin, M., Patterson, K., \& Tatsumi, I. (1999). Consistency, frequency, and lexicality effects in naming Japanese Kanji. Journal of Experimental Psychology. Human Perception and Performance, 25, 382-407.

Hino, Y., Kusunose, Y., Lupker, S. J., Kawarada, Y., \& Maekawa, M. (2011). The effect of character-to-mora consistency in the naming of Japanese Katakana words. Manuscript submitted for publication.

Hino, Y., \& Lupker, S. J. (1998). The effects of word frequency for Japanese Kana and Kanji words in naming and lexical decision: Can the dual-route model save the lexical-selection account? Journal of Experimental Psychology. Human Perception and Performance, 24, 1431-1453. doi:10.1037/0096-1523.24.5.1431

Hino, Y., Lupker, S. J., \& Pexman, P. M. (2002). Ambiguity and synonymy effects in lexical decision, naming and semantic categorization tasks: Interactions between orthography, phonology and semantics. Journal of Experimental Psychology. Learning, Memory, and Cognition, 28, 686-713.

Hino, Y., Lupker, S. J., Sears, C. R., \& Ogawa, T. (1998). The effects of polysemy for Japanese katakana words. Reading and Writing, 10, 395-424. doi:10.1023/A:1008060924384
Ijuin, M. (2008). Imi no keisan-katei niokeru hyouki no eikyou: Simulation-kenkyu karano shiten [Effect of script type in the computation process of meanings for Japanese words: Insights from simulation studies.] Paper presented at the 11th Annual Meeting of the Japanese Cognitive Neuropsychology Society, Shinjuku, Tokyo, Japan.

Jared, D., McRae, K., \& Seidenberg, M. S. (1990). The basis of consistency effects in word naming. Journal of Memory and Language, 29, 687-715.

Kimura, Y. (1984). Concurrent vocal interference: Its effects on Kana and Kanji. The Quarterly Journal of Experimental Psychology, $36 A, 117-131$.

Kinoshita, S., \& Saito, H. (1992). Effects of concurrent articulation on reading Japanese Kanji and Kana words. The Quarterly Journal of Experimental Psychology, 44A, 455-474.

Morton, J., \& Sasanuma, S. (1984). Lexical access in Japanese. In L. Henderson (Ed.), Orthographies and reading: Perspectives from cognitive psychology, neuropsychology and linguistics (pp. 2542). Hillsdale: Erlbaum.

National Language Research Institute. (1970). Denshi-keisanki niyoru shinbun no goichousa [Studies on the vocabulary of modern newspapers (Vol. 1), General descriptions and vocabulary frequency tables]. Tokyo: Shuei Shuppan.

National Language Research Institute. (1993). Bunrui-goi hyou (furoppi ban) [Thesaurus (Floppy Disk Version)]. Tokyo: Shuei Shuppan.

Saito, H. (1981). Kanji to kana no yomi niokeru keitaitekifugouka oyobi onintekifugouka no kentou [Use of graphemic and phonemic encoding in reading kanji and kana]. Japanese Journal of Psychology, 52, 266-273 (in Japanese).

Seidenberg, M. S., Waters, G. S., Barnes, M. A., \& Tanenhaus, M. K. (1984). When does irregular spelling or pronunciation influence word recognition? Journal of Verbal Learning and Verbal Behavior, 23, 383-404.

Shibahara, N., Zorzi, M., Hill, M. P., Wydell, T., \& Butterworth, B. (2003). Semantic effects in word naming: Evidence from English and Japanese Kanji. The Quarterly Journal of Experimental Psychology, 56A, 263-286.

Taft, M. (2003). Morphological representation as a correlation between form and meaning. In E. M. H. Assink \& D. Sandra (Eds.), Reading complex words: Cross-language studies (pp. 113-137). Amsterdam: Kluwer.

Taft, M. (2004). Morphological decomposition and the reverse base frequency effect. The Quarterly Journal of Experimental Psychology, 57A, 745-765.

Tamaoka, K., Kirsner, K., Yanase, Y., Miyaoka, Y., \& Kawakami, M. (2002). A Web-accessible database of characteristics of the 1,945 basic Japanese Kanji. Behavior Research Methods, Instruments, \& Computers, 34, 260-275.

Tamaoka, K., \& Makioka, S. (2004). Frequency of occurrence for units of phonemes, morae, and syllables appearing in a lexical corpus of a Japanese newspaper. Behavior Research Methods, Instruments, \& Computers, 36, 531-547.

Tamaoka, K., \& Terao, Y. (2004). Mora or syllable? Which unit do Japanese use in naming visually presented stimuli? Applied Psycholinguistics, 25, 1-27. doi:10.1017/S0142716404001018

Wydell, T. N., Butterworth, B., \& Patterson, K. (1995). The inconsistency of consistency effects in reading: The case of Japanese Kanji. Journal of Experimental Psychology. Learning, Memory, and Cognition, 21, 1155-1168.

Yamada, J. (1992). Why are Kana words named faster than Kanji words? Brain and Language, 43, 682-693.

Zhou, X., \& Marslen-Wilson, W. (2000). Lexical representation of compound words: Cross-linguistic evidence. Psychologia, 43, 47-66. 